\title{
Multidimensional Well-Being and Inequality Across the European Regions with Alternative Interactions Between the Well-Being Dimensions
}

\author{
Mehmet $\operatorname{Pinar}^{1}$ (D)
}

Accepted: 29 November 2018 / Published online: 4 December 2018

(c) The Author(s) 2018

\begin{abstract}
This paper uses recent multidimensional well-being measurements to examine multidimensional well-being and inequality across the European regions in 2000 and 2014 with the use of eleven well-being indicators from the OECD Better Life Index. We use generalized mean aggregation method with alternative parameters to allow different substitutability and complementarity levels between well-being dimensions, which range between perfect substitutability and some degree of complementarity between the dimensions, to examine well-being and inequality across the European regions. Accounting for the interactions between the well-being dimensions matters for the multidimensional well-being and inequality across the European regions. The results show that the multidimensional well-being across the European regions are relatively lower when the dimensions are more seen as complements compared to the case when they are considered to be perfect substitutes. Furthermore, there is also a higher degree of multidimensional inequality across the European regions when the dimensions are considered to have some complementarity. Changes in well-being dimensions between 2000 and 2014 indicates that multidimensional well-being improved and inequality decreased in the personal and community well-being categories, but remained unchanged in material well-being category across the European regions irrespective of interaction levels between well-being dimensions. Policy implications of these multidimensional well-being indices are also evaluated by using these indices to determine the eligible regions for the European Union structural funds where the number eligible regions shows some variation depending on whether the dimensions are perfect substitutes or more of complements.
\end{abstract}

Keywords Regional well-being $\cdot$ Better Life Index $\cdot$ Multidimensional well-being · Multidimensional inequality $\cdot$ Interaction between dimensions $\cdot$ Europe

Electronic supplementary material The online version of this article (https://doi.org/10.1007/s1120 5-018-2047-4) contains supplementary material, which is available to authorized users.

Mehmet Pinar

mehmet.pinar@edgehill.ac.uk

1 Business School, Edge Hill University, St Helens Road, Ormskirk, Lancashire L39 4QP, UK 


\section{Introduction}

It has been widely accepted that well-being is a multidimensional phenomenon (Fleurbaey and Blanchet 2013) which requires consideration of many dimensions of well-being. For instance, the European Commission's "Going beyond GDP" initiative ${ }^{1}$ and Stiglitz et al. (2009) point out that the well-being progress should be examined by considering wellbeing indicators that are beyond standard of living and should include dimensions of wellbeing such as health, education, political voice and governance, environmental factors, among other dimensions.

Until recently, the analysis of the multidimensional well-being has been at country level. For instance, the most commonly known composite index measuring multidimensional well-being is the United Nations' Development Programme (UNDP)'s Human Development Index (HDI), which offers countries' average achievement in income, education and health dimensions (Malik 2013). Environmental Sustainability Index (ESI), on the other hand, aggregates various dimensions of well-being and sustainability (Esty et al. 2005) by using the weighted average achievements across different set of dimensions. Finally, OECD's Better Life Index (BLI) offers multidimensional well-being index by aggregating achievements in 11 indicators through preferences of individuals on different well-being indicators (Durand 2015). ${ }^{2}$ Only very recently, the OECD has proposed a computation of the BLI at a regional level thanks to the availability of well-being macro-level data at regional level for OECD countries (OECD 2014) enabling one to construct regional wellbeing indices, which is the aim of this paper.

Above-mentioned composite indices provide a more holistic measure of well-being by including more dimensions into measuring social progress. However, most of the composite indices aggregated through weighted averages where each dimension is given a relative weight suggesting its intrinsic importance (Alkire and Santos 2014). However, one of the characteristics of weighted average aggregation that is overlooked by public and policymakers is that this aggregation method assumes perfect substitution between well-being dimensions [see Decancq and Lugo (2013) for a detailed discussion on this issue]. This has been something that has been taken into account by the new aggregation method of the HDI, a geometric mean, where the intention of the UNDP is to make sure that the poor performances in some dimensions are reflected in the HDI since unbalanced achievements across the well-being dimensions are reflected in the composite HDI scores. For instance, Zambrano (2014) examines the normative properties of geometric mean aggregation and suggests that the geometric mean aggregation of the HDI penalizes both low and uneven achievements across all dimensions of human development, whereas the old formulation is not sensitive to such uneven development. This is something that is also in the lines with the Cobb-Douglas utility (production) function since education and health dimensions are considered to be part of the production function where achievements in education and health complement each other to lead different levels of income per capita across

\footnotetext{
1 See http://ec.europa.eu/environment/beyond_gdp/background_en.html for details.

2 The choice of weights is still based on individual preferences and can be considered as paternalistic (see Decancq et al. 2015). Alternative well-being measures based on equivalent incomes use a flexible specification where individual preferences determine the curvature of the iso-well-being curves [see e.g., Fleurbaey and Blanchet (2013) for an extensive survey and Decancq and Schokkaert (2016) for an application with European data, for instance].
} 
countries. ${ }^{3}$ In this respect, we use generalized mean aggregation method, which is general enough to take into account the normative judgments of individuals and policymakers with respect to the weight allocation across well-being dimensions and also the interaction levels between the well-being dimensions [see e.g., Decancq (2017) for a recent implementation of the generalized mean aggregation method to obtain distribution-sensitive wellbeing scores for the OECD countries].

Taking into account interactions between well-being dimensions (i.e., whether wellbeing dimensions are substitutes or complements) are particularly important since this would give different signals to regions to improve their multidimensional well-being. For instance, if the multidimensional well-being index obtained with arithmetic mean aggregation (i.e., dimensions are perfect substitutes), policymaker in a given region can choose to improve "easy" dimensions to improve overall well-being, which can then lead to unbalanced composition of development. For instance, if the dimensions are considered to be perfect substitutes, an improvement in any dimension would be sufficient to improve overall index outcome and policymakers could choose to improve the dimensions that are less costly (or relatively easier to manipulate). Whereas, if two dimensions are more seen as complements, then a policymaker should prioritize balanced improvement in both dimensions since the uneven achievements across all dimensions would not improve the wellbeing as much as the balanced ones. Hence, identifying and taking into account these interactions are important since different interaction levels across well-being dimensions would prioritise different policies to improve the aggregate well-being outcomes. In this respect, it is important to understand the priorities set by the policymakers in Europe to determine the levels of interaction across the well-being dimensions when constructing a regional well-being index for the European regions.

One of the first objectives of the European Union (EU) since its establishment has been to decrease the income disparities across its regions by allocating funds to regions that have gross domestic product (GDP) per inhabitant less than $75 \%$ of the EU average, which is found to be an effective way of decreasing the income disparities across regions (see e.g., Bosker 2009; Becker et al. 2013). Recent policy documents on the regional development also consider the inclusion of social and environmental dimensions beyond GDP per capita when determining the allocation of EU structural funds (European Committee of the Regions 2011) suggesting the relevance of multidimensional well-being in policymaking. Furthermore, European Commission (EC)'s goals set for 2020 aim to promote "a balanced and sustainable pattern of territorial development" by increasing employment, investment in $R \& D$ and tertiary degrees, and decreasing emissions and the poverty across the regions (European Commission 2010). Hence, EC clearly suggests that their aim is to promote balanced achievements across various well-being dimensions and regions, which gives an indication to consider the dimensions more of complements. Hence, in this paper, we offer a generalized mean aggregation method that provides an aggregation method that is flexible enough to take into account different degrees of complementarity between the wellbeing dimensions. In other words, given the priority of balanced and sustainable pattern of territorial development, we prioritize even achievements across well-being dimensions (or penalize uneven achievements across well-being dimensions) by allowing dimensions not to be perfect substitutes (or allowing dimensions to be complementary). Although we offer an aggregation where the dimensions are seen more of complements, we also compute

\footnotetext{
3 See for example Glaeser et al. (2004) for education's importance in economic growth, and Behrman and Rosenzweig (2004) for health's effect on economic growth.
} 
well-being indices where the dimensions are considered as perfect substitutes to compare the outcomes obtained with different approaches.

Overall, contributions of this paper are threefold. Firstly, this paper offers multidimensional well-being and inequality measures for European regions which goes beyond the GDP per capita comparisons by integrating more dimensions into analysis. ${ }^{4}$ Secondly, we propose an aggregation methodology that is flexible enough to capture the interactions between the well-being dimensions. ${ }^{5}$ In particular, we consider that the well-being dimensions to be seen more of complements which enables one to capture how balanced the achievements across the dimensions are. Thirdly, we assess the potential policy implications of these indices by determining the eligible regions for the EU structural funds if these indices are used as eligibility criteria rather than the GDP per capita.

The remainder of the paper is organized as follows. The next section, we introduce wellbeing dimensions and categories that are used in the construction of regional well-being index. We also offer generalized mean aggregation methodology which allows different degree of substitution and complementary across well-being dimensions. Section 3 presents the multidimensional well-being and inequality measures, ranking analysis, and overtime changes in multidimensional well-being and inequality between 2000 and 2014 for the European regions. Section 4 provides analysis on how normative preferences could lead to distinctive policy outcomes when EU structural funds are allocated based on the composite well-being indices. Finally, Sect. 5 concludes.

\section{Construction of Multidimensional Well-Being Index}

Constructing a multidimensional well-being index is a non-trivial task. In general, it requires the definition of the concept to be measured, selection of the indicators, normalization of the indicators, and the choice of the aggregation method [see OECD (2008) for detailed steps on the construction of composite indicators].

In general, there are two conceptual measurement models: formative or reflective (see e.g., Coltman et al. 2008; Diamantopoulos et al. 2008). In general, reflective measurement model's causality is from the concept to the indicators where the opposite direction of causality (from the indicators to the concept) is the case for the formative measurement model. Since the objective of this paper is to measure regional well-being, and that the well-being depends on the indicators and not vice versa, this paper follows the formative measurement model (see e.g., Mazziotta and Pareto $(2016,2018)$ for further discussion on the difference between reflective and formative models when measuring well-being). In the next sub-sections, we will offer the well-being dimensions and categories chosen to measure well-being, normalization and aggregation methods to obtain composite well-being indices for the European regions.

\footnotetext{
${ }^{4}$ Majority of the regional inequality across the European regions are based on income per capita (see e.g., Hoffmeister 2009; Fredriksen 2012; Doran and Jordan 2013) where we offer a multidimensional inequality measures for the European regions in this paper.

5 Even though multidimensional well-being (or poverty) in Europe is evaluated (see e.g., Bárcena-Martín et al. 2014; Binelli et al. 2015), these composite measures allow perfect substitution between the dimensions, but did not consider the complementarity between the well-being dimensions (i.e., sensitivity of policy makers to the evenness of achievements across well-being dimensions), which we take into account in this paper.
} 


\subsection{Well-Being Dimensions and Categories}

We use the nine dimensions considered in the OECD regional well-being index (OECD 2016) and compiled them into three categories of well-being (i.e., material, personal and community) to track the progress in three general categories of well-being in the regions of Europe.

Table 1 offers the dimensions and categories of well-being and indicators used in each dimension, and the details of how each indicator is measured. Material well-being category consists of achievements of the regions in income (measured by the average household disposable income per capita), jobs (measured by the employment and unemployment rates), and housing (number of rooms available per person) dimensions. Personal well-being category consists of education (measured by the share of the labor force with at least secondary education), health (measured by the life expectancy and mortality rates), and access to services (which measures the share of households with broadband access) dimensions. Finally, community well-being category includes the civic engagement (measured by voter turnout), environmental quality (measured by air pollution levels) and safety (measured by homicide rates) dimensions. For potential policy implications of the proposed index, we only consider achievements of European regions in these dimensions in 2000 and $2014 .^{6}$

\subsection{Normalization Procedure}

Since the indicators are measured in different units, we need to normalize the indicators prior to the aggregation. There are numerous methods of normalization such as standardization (or z-scores), rescaling (or min-max), and distance to reference points, and one can choose a specific normalization procedure depending on the problem at hand [see OECD (2008) for further discussion on the benefits and disadvantages of various normalization procedures]. In this paper, we follow the OECD approach to normalize the indicators in order to have comparisons across space and time. To avoid the effects of large outliers in each indicator, indicators are censored in the lower and upper limits (i.e., 4th and 96th percentile of the distribution). ${ }^{7}$ Then min-max formula is used to normalize all indicators between 0 and 1 :

$$
z_{i j}^{t}=\left[\frac{X_{i j}^{t}-\min \left(X_{j}\right)}{\max \left(X_{j}\right)-\min \left(X_{j}\right)}\right]
$$

where $z_{i j}^{t}$ and $X_{i j}^{t}$ are normalized and actual outcomes in region $i$ for a given indicator $j$ at a given time $t$, respectively. $\max \left(X_{j}\right)$ and $\min \left(X_{j}\right)$ represent the maximum and minimum value

\footnotetext{
${ }^{6}$ We consider the regions of 24 OECD countries that are located in Europe. 21 of these countries are part of the EU and 3 of them are not part of the EU (Iceland, Norway, and Switzerland). We do not include regions of seven countries that are part of the EU (Bulgaria, Croatia, Cyprus, Latvia, Lithuania, Malta, Romania) since they are not OECD member and hence we do not have any data for these regions. 2000 and 2014 reference points were made by the OECD for comparison reasons; however, closest available data is used for year 2000 and 2014. See Table 3 of OECD (2016) for further details.

${ }^{7}$ Note that OECD uses 10th and 90th percentiles of the homicide data as lower and upper limits to avoid low and high clusters of the data.
} 


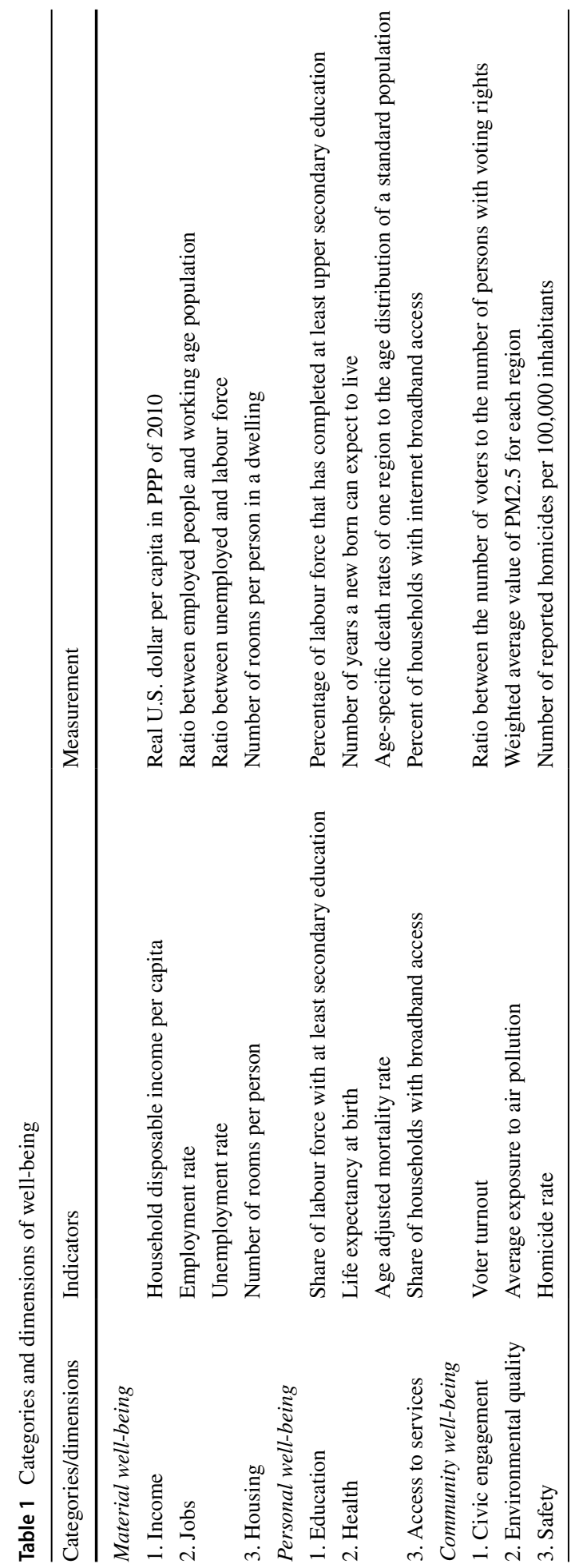


for a given indicator $j$ during the period of the comparison. ${ }^{8}$ It should be noted that the higher normalized values represent higher welfare levels. ${ }^{9}$ Once the indicators are normalized, we then have normalized scores in nine dimensions. ${ }^{10}$

Table 2 presents the Spearman and Kendall rank correlation matrices for the nine wellbeing dimensions across the European regions where the first and second rows between pairs of dimensions represent the Spearman and Kendall rank correlation coefficients between pairs of dimensions, respectively. Even though most of the well-being dimensions are positively correlated, some well-being dimensions are either negatively correlated with each other or some of them have no significant rank correlation coefficients. If all wellbeing dimensions were highly and positively correlated, any index constructed from these well-being dimensions would hardly provide additional information or would have been redundant [see e.g., McGillivray (2005), Cahill (2005), Berenger and Verdier-Chouchane (2007), Permanyer (2011), Foster et al. (2013) among many others that examine the redundancy of composite indices based on correlation analysis]. Hence, the existence of negative and insignificant correlation coefficients (and in some cases low positive correlation coefficients) between well-being dimensions is reassuring to construct multidimensional well-being indices as the index would provide additional set of information. In the next subsection, we propose the generalized mean aggregation methodology, which we use to obtain multidimensional well-being indices.

\subsection{Aggregation Method}

As discussed before, we offer a generalized mean aggregation method which is flexible enough to take into account various value judgments of the decision maker (individuals and/or policymakers): a weighting vector for the dimensions and a parameter that express the degree of substitution (complementarity) between the dimensions. To capture the degree of substitution (complementarity) between the well-being dimensions, normalized achievement levels can be aggregated by taking a generalized weighted mean of order $\beta$ to obtain a multidimensional well-being index as follows:

$$
W I_{i}^{t}=\left(\sum_{j=1}^{d} w_{j} \times\left(z_{i j}^{t}\right)^{\beta}\right)^{\frac{1}{\beta}}
$$

where $w_{j}$ is the weight attached to well-being dimension $j, z_{i j}^{t}$ is the normalized achievement level of a region $i$ in dimension $j$ at time $t$. The parameter $\beta$ is the main parameter of

\footnotetext{
${ }^{8}$ As any normalization procedure, the one adapted by the OECD have some defects such as the rigidity of a method that considers a range $[0,1]$ or the problem of variability assigned to elementary indicators [see e.g., OECD (2008), Mazziotta and Pareto (2017) for further discussion on this issue]. However, we adapt the same normalization procedure as the contribution of this paper is to examine the effect of different parameter choices in aggregation procedure on the composite scores and rankings.

${ }_{9}^{9}$ For indicators where lower value correspond to higher welfare such as the homicide rate, air pollution, mortality rate and unemployment rate, normalized values are subtracted from one.

${ }^{10}$ If a dimension has more than one indicator, we obtain the normalized achievement level in that dimension by averaging the achievements in indicators used under that dimension.
} 


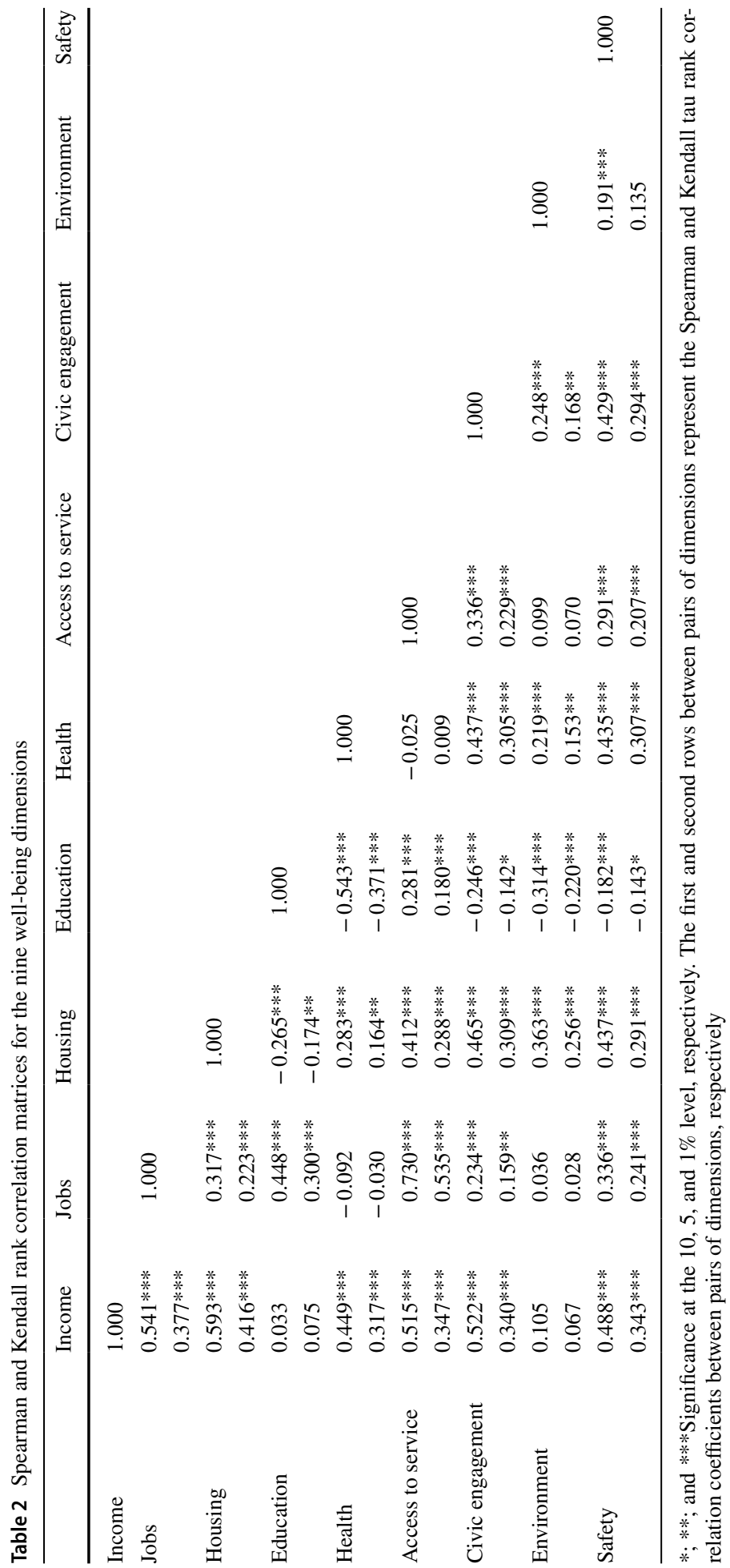


interest in this paper which captures the value judgment of the decision maker with respect to the degree of substitution (complementarity) between the dimensions. ${ }^{11}$

Clearly, when $\beta=1$, the aggregation pins down to arithmetic mean aggregation where there is a perfect substitutability between the dimensions. In this case, a lower achievement in one dimension can be compensated by the higher achievement in another dimension. In this case, the regions can concentrate on some dimensions which can be easily manipulated (or less costly to achieve) to increase their regional well-being given the compensation across dimensions, which might lead to unbalanced achievement across the well-being dimensions. For instance, one of the criticisms of the arithmetic mean aggregation of the dimensions of the HDI was that perfect substitutability between dimensions led to uneven achievements where some research papers suggested a lower degree of substitutability (or some level of complementarity) between dimensions [e.g. Herrero et al. (2010) suggested the use of geometric mean to aggregate the dimensions of the HDI]. ${ }^{12}$

Another popular use with the above case is obtained when $\beta$ is set to 0 where the aggregation function becomes a geometric mean. This is referred as the Cobb-Douglas utility function (see the recent use of this aggregation by the UNDP's HDI). ${ }^{13}$ In this case, trade-offs across the well-being dimensions depend on both relative weights and level of achievements across well-being dimensions. A percentage decrease in one dimension can be compensated by the percent increase in other dimensions. In this case, the aggregation would penalize regions with unbalanced achievements in the well-being dimensions, hence reflecting some degree of complementarity between the dimensions rather than perfect substitutability. ${ }^{14}$

Beyond these two special cases, when parameter $\beta$ decreases, this makes it increasing difficult to compensate a decrease in one dimension by an increase in another. In particular, when $\beta$ is set to $-\infty$, multidimensional well-being of a region is determined by the worst outcome across all dimensions of well-being. In other words, change in any other dimension which is not the worst achieved dimension does not affect the composite well-being outcome. For the case when $\beta$ is set to $-\infty$, a region that wants to improve the composite well-being is implied to focus on the dimension in which the achievement level is the worst one. This choice clearly favors a case requiring regions to promote perfectly balanced achievements between the well-being dimensions.

In the evaluation of complex multidimensional well-being (sustainability) regional (country) performances, the choice of various parameters in the aggregation procedure conveys the preferences of decision makers (e.g., policymakers and the general public). Given the complexity of aggregation procedure for the decision makers, there is a stream of literature that elicit decision makers' preferences through questionnaire to obtain necessary parameters for the aggregation to increase the acceptability and applicability of these aggregation methods in policy-making [see e.g., Guh et al. (2008) for discussion

\footnotetext{
11 See Decancq and Lugo (2013) for the list of papers using this method to obtain multidimensional wellbeing index.

12 Similarly, Ravallion (1997, 2012) calculated the implicit trade-offs between the dimensions of the HDI and found that the valuation of some the dimensions are way higher than the economic returns or cost of improving the dimension.

13 For the formal axioms of the generalized mean aggregation (or some form of generalized mean aggregation), we refer the interested readers to Chakravarty (2003), Herrero et al. (2010), Chakravarty (2011), Zambrano (2014, 2017).

14 See for example Herrero et al. (2010) and Klugman et al. (2011) for the detailed comparison of arithmetic and geometric mean aggregation of the dimensions of the HDI.
} 
generalized mean aggregation]. For the derivation of questionnaires to obtain decisionmaker preferences on interactions between the well-being (sustainability) indicators, interested readers are referred to Meyer and Ponthiere (2011), Garmendia and Gamboa (2012), Rowley et al. (2012), Carraro et al. (2013), Merad et al. (2013), Pinar et al. (2014), Bertin et al. (2018) among many others. In this paper, we obtain overall regional well-being outcomes in three categories (i.e., material, personal and community) by allowing different degrees of complementarity (substitution) between well-being dimensions by choosing specific $\beta$ parameters while keeping the weights between the dimensions equal. There is an extensive literature concerning the effects of choice of weights on both the ranking and composite achievement levels (see e.g., Chowdhury and Squire 2006; Cherchye et al. 2008; Permanyer 2011; Foster et al. 2013; Pinar et al. 2013, 2015, 2017; Tofallis 2013; Athanassoglou 2015). However, in this paper, our main focus is to allow different degrees of substitutability (complementarity) between the dimensions when obtaining composite well-being indices and to examine whether this normative preference has any effect on the composite scores and allocation of resources across the European regions. Hence, when obtaining the overall, material, personal and community multidimensional well-being index, we keep the allocation of the weights between the dimensions equal. ${ }^{15}$ For instance, the BLI allows its users to choose relative weight allocation across well-being dimensions in its interactive web application, however, this feature does not allow individuals to reflect their preferences on whether they consider the well-being dimensions as substitutes and/or complements of each other. ${ }^{16}$ In this paper, we will examine the effect of this choice on the multidimensional well-being achievements of the European regions and also examine how this choice affects the multidimensional inequality across the European regions in the next section.

\section{Multidimensional Well-Being Indices and Inequality}

To obtain overall multidimensional well-being outcomes and multidimensional well-being outcomes for each category (i.e., material, personal, and community) for 213 regions of Europe, ${ }^{17}$ we use three $\beta$ parameters: 1 (i.e., arithmetic mean aggregation), 0 (i.e., geometric mean aggregation), ${ }^{18}$ and -1 (an aggregation that allows higher degree of complementarity between the dimensions). ${ }^{19}$ In this section, we concentrate on the composite achievement levels in different categories and overall multidimensional well-being in 2014, but we will also analyze the over-time improvements in composite well-being outcomes and changes in the multidimensional inequality in the next sub-sections.

\footnotetext{
15 We allocate weights of $1 / 9$ to each dimension when obtaining overall well-being index, and allocate $1 / 3$ weight to dimensions that belong to the material, personal and community categories when obtaining multidimensional well-being indices in each category, respectively.

16 See http://www.oecdbetterlifeindex.org for the interactive web application of the BLI.

17 See Table 1 of supplementary material for the full list of European regions.

18 For instance, the new aggregation method of the HDI (i.e., geometric mean) provides a middle ground between perfect substitution and complementarity between dimensions, which is characterized by some level of both complementarity and substitutability, and is well-suited for capability approach [see e.g., for Klugman et al. (2011) for further discussion on this].

19 One can also allow higher degree of complementarity between dimensions by allowing $\beta$ parameter to be less than -1 if that person is more concerned about the balanced nature of achievements between the dimensions.
} 
Table 3 provides descriptive statistics on the welfare dimensions and composite wellbeing indices in $2014 .^{20}$ Average achievement levels of the European regions in jobs, civic engagement and environment dimensions are lower than that of income dimension, yet the average achievement levels in housing, education, health, access to services and safety dimensions are higher than that of income dimension. On the other hand, when we look at the inequality measures (i.e., coefficient of variation and Gini coefficients), regional inequality in income dimension is relatively larger than in any other well-being dimensions. $^{21}$ When we move to the descriptive statistics of the composite scores obtained in 2014 with the use of different set of $\beta$ parameters, we observe clear patterns in average achievement levels and inequality measures. While the average composite scores in overall, material, personal and community well-being categories increase with the increase in the $\beta$ parameter, multidimensional inequality measures across the European regions decrease with the increase in the parameter of $\beta .^{22}$ In other words, if decision makers (individuals and/or policymakers) consider the well-being dimensions as complements of each other at some degree or prefer and prioritize rounded achievements between well-being dimensions (i.e., the cases when $\beta=0$ and $\beta=-1$ ), composite achievement scores are lower compared to the case when the dimensions are considered perfect substitutes of each other (i.e., the case when $\beta=1$ ). This is an expected outcome since complementarity at some degree between the dimensions leads to relatively lower composite scores for the regions that have unrounded achievements between the well-being dimensions. ${ }^{23}$ On the other hand, when decision makers allow perfect substitution between the dimensions (i.e., the case when $\beta=1$ ), multidimensional inequality measures are the lowest compared to inequality measures in other individual dimensions. For instance, multidimensional inequality in material, personal and community categories (i.e., Gini coefficients are 0.189, 0.068, and 0.126 , respectively) are lower than the inequality in the dimensions that are used to obtain composite scores in these categories. The reason why we observe a higher degree of multidimensional inequality across European regions when the dimensions are considered as complements of each other at some degree is that the composite achievement scores in the regions that have balanced achievements between the dimensions and the composite scores in regions with unbalanced achievements between the dimensions diverge from each other. $^{24}$

\footnotetext{
${ }^{20}$ Note that both the achievement levels and inequality measures refer to normalized well-being dimensions.

${ }^{21}$ All inequality measures presented in the paper are population weighted measures where we use the regions' populations in 2000 and 2014 to obtain population weighted coefficient of variation and Gini coefficients.

${ }^{22}$ Assessment of well-being and inequality in different well-being categories (i.e., community, personal, material, and overall well-being) can be considered as influence analysis (see e.g., Mazziotta and Pareto 2017) to examine robustness of composite indices and inequality measures when some well-being dimensions are excluded from the analysis.

${ }^{23}$ Note that we conducted our analysis with alternative $\beta$ parameters ranging between -20 and +20 where we observed a similar pattern in multidimensional well-being achievements and inequality; hence we do not present the results to preserve space but these results are available upon request from author.

${ }^{24}$ For instance, consider two regions with the same population that have achievements scores in three dimensions as follows: region $\mathrm{A}=(0.5,0.5,0.5)$ and Region $\mathrm{B}=(0.4,0.5,0.6)$. The composite achievements with $\beta=-1,0$ and 1 for region $\mathrm{A}$ and $\mathrm{B}$ are $(0.5,0.5,0.5)$ and $(0.4865,0.4932,0.5)$, respectively. Achievement with the perfect substitution between the dimensions leads to the same composite achievement (i.e., 0.5) with no inequality. When the degree of complementarity between the dimensions increases (i.e., when $\beta$ parameter decreases), composite achievement of region $\mathrm{B}$ decreases, which leads to higher inequality between two regions.
} 
Table 3 Well-being achievements and inequality among European regions

\begin{tabular}{|c|c|c|c|c|}
\hline Dimensions/composite indices & Mean & Median & $\begin{array}{l}\text { Coefficient of } \\
\text { variation }\end{array}$ & Gini coefficient \\
\hline Income & 0.656 & 0.731 & 0.422 & 0.236 \\
\hline Jobs & 0.635 & 0.689 & 0.414 & 0.227 \\
\hline Housing & 0.695 & 0.769 & 0.386 & 0.207 \\
\hline Education & 0.711 & 0.779 & 0.319 & 0.170 \\
\hline Health & 0.796 & 0.831 & 0.232 & 0.124 \\
\hline Access to services & 0.834 & 0.829 & 0.134 & 0.076 \\
\hline Civic engagement & 0.604 & 0.624 & 0.411 & 0.230 \\
\hline Environment & 0.590 & 0.583 & 0.361 & 0.202 \\
\hline Safety & 0.766 & 0.847 & 0.297 & 0.152 \\
\hline Overall well-being $(\beta=-1)$ & 0.563 & 0.706 & 0.493 & 0.259 \\
\hline Overall well-being $(\beta=0)$ & 0.627 & 0.728 & 0.342 & 0.180 \\
\hline Overall well-being $(\beta=1)$ & 0.698 & 0.747 & 0.192 & 0.104 \\
\hline Material well-being $(\beta=-1)$ & 0.606 & 0.704 & 0.472 & 0.259 \\
\hline Material well-being $(\beta=0)$ & 0.627 & 0.712 & 0.426 & 0.234 \\
\hline Material well-being $(\beta=1)$ & 0.662 & 0.721 & 0.339 & 0.189 \\
\hline Personal well-being $(\beta=-1)$ & 0.733 & 0.786 & 0.225 & 0.112 \\
\hline Personal well-being $(\beta=0)$ & 0.755 & 0.791 & 0.184 & 0.091 \\
\hline Personal well-being $(\beta=1)$ & 0.780 & 0.797 & 0.126 & 0.068 \\
\hline Community well-being $(\beta=-1)$ & 0.566 & 0.635 & 0.419 & 0.222 \\
\hline Community well-being $(\beta=0)$ & 0.596 & 0.656 & 0.368 & 0.193 \\
\hline Community well-being $(\beta=1)$ & 0.653 & 0.682 & 0.231 & 0.126 \\
\hline
\end{tabular}

Overall, above comparisons show that policymaker's valuation of well-being dimensions (i.e., whether they consider dimensions as perfect substitutes or some degree of complements, or whether they prioritize balanced achievements between the dimensions or not) leads to extremely different levels of achievement and inequality in the European regions, which may alter the policy interventions that are based on composite indices. In the next section, we will examine whether normative preferences on well-being dimensions (whether dimensions are considered as complements or substitutes) have any effect on decision making when composite indices are used as a criteria to allocate the EU structural funds. However, before the evaluation of the policy implications of these indices, we first examine the multidimensional well-being and inequality in the European countries and assess the within- and cross-country variation in multidimensional well-being scores and inequality.

\subsection{Multidimensional Well-Being and Inequality in European Countries}

In this subsection, we examine the average achievements in income, overall, material, personal, and community composite well-being outcomes among European countries in 2014. We also look at within- and cross-country multidimensional well-being inequality in the European regions. Table 4 summarizes the average achievement levels of European countries in income, overall, material, personal, and community composite well-being outcomes (with different $\beta$ parameters), and within- and cross-country inequality in income 
dimension and composite indices in 2014. This table is quite heavy to follow but let us provide the details of the general patterns of achievements and inequality measures across the European countries. We can see that the within-country income inequality is small in relatively rich countries and large for the relatively poor countries suggesting a negative correlation between average income of a country and within-country income inequality (see Fig. 1 which plots the average income and within-country income inequality in the European countries). ${ }^{25}$ Similar pattern is observed in overall, material, and community well-being when well-being dimensions are considered to be complements at some degree (i.e., cases when $\beta \leq 0$ ). Countries that have a composite achievement level of $0.5-0.6$ or above (below) have relatively low (high) levels of within-country inequality in overall, material and community well-being indices. With the exception of Portugal, both withinand cross-country inequality levels in personal well-being are relatively lower compared to other multidimensional well-being categories suggesting relatively balanced achievements between the education, health and access to services dimensions. ${ }^{26}$ Finally, when $\beta$ parameter is decreased from 0 to -1 (i.e., higher degree of complementarity between the dimensions), we observe that within- and cross-country inequality increases and the increase in within-country inequality is relatively higher for the countries that have lower multidimensional well-being scores. ${ }^{27}$

When well-being dimensions are considered to be perfect substitutes (i.e., when $\beta=1$ ), by definition, overall, material, personal, and community well-being increases (or at most remains unchanged) compared to the cases when $\beta \leq 0$. In particular, increases in the average achievement levels in each multidimensional well-being category are relatively higher for the set of countries that have unbalanced achievements between the dimensions (i.e., set of countries that have multidimensional achievement levels in each category that are less than $0.5-0.6$ when $\beta=0$ ). For instance, when $\beta$ parameter is increased to 1 from 0 (i.e., when well-being dimensions are aggregated with arithmetic mean rather than geometric mean), overall well-being scores of Estonia, Greece, Slovak Republic, Portugal, Poland, and Italy increased by $0.36,0.27,0.26,0.20,0.16$, and 0.14 , respectively. On the other hand, there have been limited increments in the multidimensional well-being scores of the regions that belong to countries that are relatively wealthier and have balanced achievements between the dimensions when $\beta$ parameter is increased from 0 to $1 .^{28}$ Finally, there is smaller withincountry inequality when there is perfect substitution between the dimensions, which then leads to a smaller cross-country inequality in multidimensional well-being categories. ${ }^{29}$

Overall, there are distinctive differences in multidimensional well-being scores, and within- and cross-country inequality measures when dimensions are considered to be

\footnotetext{
25 The correlation coefficient between average income and within-country income inequality (i.e., Gini coefficients for income distribution within the country) is -0.79 .

26 See Figure 1 of supplementary material which plots the average overall, material, personal, and community well-being and within-country inequality with respective multidimensional well-being category when $\beta=0)$.

27 There are two expectations to this general trend. Overall well-being inequality in Estonia and material well-being inequality in Slovak Republic is higher when $\beta=0$ than that of when $\beta=-1$.

${ }^{28}$ For instance, multidimensional well-being achievements in each category increased at most by 0.06 in Norway, Sweden, Germany, Finland, Iceland, the UK, Denmark, Austria, Netherlands, France, Ireland, and Belgium when $\beta$ parameter is increased from 0 to 1 .

29 See Figure 2 of supplementary material that plots the average overall, material, personal and community well-being in countries and within-country inequality in each respective multidimensional well-being when $\beta=1$.
} 
Table 4 Income and multidimensional well-being (inequality) across the European countries in 2014

\begin{tabular}{|c|c|c|c|c|c|c|c|c|c|c|c|c|c|c|}
\hline \multirow[t]{2}{*}{ Country } & \multicolumn{2}{|c|}{ Income } & \multicolumn{2}{|c|}{$\begin{array}{l}\text { Overall } \\
(\beta=-1)\end{array}$} & \multicolumn{2}{|c|}{$\begin{array}{l}\text { Overall } \\
(\beta=0)\end{array}$} & \multicolumn{2}{|c|}{$\begin{array}{l}\text { Overall } \\
(\beta=1)\end{array}$} & \multicolumn{2}{|c|}{$\begin{array}{l}\text { Material } \\
(\beta=-1)\end{array}$} & \multicolumn{2}{|c|}{$\begin{array}{l}\text { Material } \\
(\beta=0)\end{array}$} & \multicolumn{2}{|c|}{$\begin{array}{l}\text { Material } \\
(\beta=1)\end{array}$} \\
\hline & $\mathrm{Av}$ & Gini & Av & Gini & Av & Gini & Av & Gini & $\mathrm{Av}$ & Gini & Av & Gini & $\mathrm{Av}$ & Gini \\
\hline Austria & 0.95 & 0.02 & 0.74 & 0.04 & 0.76 & 0.03 & 0.78 & 0.03 & 0.81 & 0.04 & 0.82 & 0.04 & 0.83 & 0.04 \\
\hline Belgium & 0.71 & 0.06 & 0.64 & 0.07 & 0.69 & 0.06 & 0.73 & 0.04 & 0.72 & 0.10 & 0.74 & 0.08 & 0.77 & 0.06 \\
\hline Czech Rep. & 0.23 & 0.20 & 0.39 & 0.17 & 0.46 & 0.12 & 0.54 & 0.05 & 0.35 & 0.10 & 0.41 & 0.08 & 0.47 & 0.07 \\
\hline Denmark & 0.57 & 0.02 & 0.76 & 0.01 & 0.77 & 0.01 & 0.78 & 0.01 & 0.69 & 0.01 & 0.70 & 0.01 & 0.71 & 0.01 \\
\hline Estonia & 0.06 & 0.53 & 0.00 & 0.06 & 0.17 & 0.16 & 0.53 & 0.06 & 0.11 & 0.51 & 0.17 & 0.41 & 0.37 & 0.07 \\
\hline Finland & 0.63 & 0.08 & 0.77 & 0.03 & 0.78 & 0.02 & 0.79 & 0.02 & 0.69 & 0.04 & 0.69 & 0.04 & 0.70 & 0.04 \\
\hline France & 0.80 & 0.07 & 0.73 & 0.05 & 0.74 & 0.04 & 0.76 & 0.04 & 0.67 & 0.05 & 0.68 & 0.04 & 0.69 & 0.04 \\
\hline Germany & 0.92 & 0.06 & 0.78 & 0.02 & 0.80 & 0.02 & 0.81 & 0.02 & 0.91 & 0.04 & 0.92 & 0.04 & 0.92 & 0.04 \\
\hline Greece & 0.15 & 0.53 & 0.01 & 0.80 & 0.16 & 0.14 & 0.43 & 0.06 & 0.09 & 0.47 & 0.13 & 0.41 & 0.23 & 0.14 \\
\hline Hungary & 0.09 & 0.44 & 0.24 & 0.27 & 0.36 & 0.12 & 0.46 & 0.06 & 0.14 & 0.33 & 0.19 & 0.23 & 0.28 & 0.13 \\
\hline Iceland & 0.51 & 0.00 & 0.75 & 0.02 & 0.78 & 0.01 & 0.81 & 0.01 & 0.62 & 0.00 & 0.64 & 0.00 & 0.67 & 0.00 \\
\hline Ireland & 0.71 & 0.04 & 0.70 & 0.02 & 0.72 & 0.02 & 0.73 & 0.01 & 0.69 & 0.02 & 0.71 & 0.01 & 0.72 & 0.01 \\
\hline Italy & 0.65 & 0.19 & 0.38 & 0.40 & 0.51 & 0.21 & 0.65 & 0.09 & 0.51 & 0.25 & 0.54 & 0.21 & 0.58 & 0.17 \\
\hline Netherlands & 0.58 & 0.07 & 0.73 & 0.03 & 0.75 & 0.02 & 0.76 & 0.01 & 0.73 & 0.03 & 0.74 & 0.03 & 0.75 & 0.02 \\
\hline Norway & 0.88 & 0.05 & 0.87 & 0.01 & 0.87 & 0.01 & 0.88 & 0.01 & 0.89 & 0.01 & 0.89 & 0.01 & 0.89 & 0.01 \\
\hline Poland & 0.21 & 0.23 & 0.19 & 0.42 & 0.30 & 0.22 & 0.46 & 0.05 & 0.14 & 0.37 & 0.18 & 0.33 & 0.28 & 0.15 \\
\hline Portugal & 0.40 & 0.10 & 0.11 & 0.44 & 0.33 & 0.16 & 0.53 & 0.03 & 0.51 & 0.06 & 0.53 & 0.06 & 0.56 & 0.07 \\
\hline Slovak Rep. & 0.24 & 0.38 & 0.04 & 0.87 & 0.20 & 0.18 & 0.45 & 0.05 & 0.21 & 0.15 & 0.25 & 0.18 & 0.29 & 0.20 \\
\hline Slovenia & 0.35 & 0.05 & 0.42 & 0.07 & 0.49 & 0.04 & 0.55 & 0.03 & 0.43 & 0.03 & 0.44 & 0.03 & 0.46 & 0.03 \\
\hline Spain & 0.54 & 0.19 & 0.44 & 0.31 & 0.54 & 0.18 & 0.66 & 0.06 & 0.34 & 0.36 & 0.40 & 0.30 & 0.51 & 0.14 \\
\hline Sweden & 0.71 & 0.08 & 0.81 & 0.01 & 0.82 & 0.01 & 0.83 & 0.01 & 0.71 & 0.02 & 0.72 & 0.03 & 0.73 & 0.03 \\
\hline Switzerland & 0.81 & 0.07 & 0.37 & 0.13 & 0.60 & 0.03 & 0.72 & 0.02 & 0.74 & 0.04 & 0.76 & 0.04 & 0.78 & 0.04 \\
\hline UK & 0.80 & 0.10 & 0.76 & 0.03 & 0.77 & 0.03 & 0.78 & 0.03 & 0.82 & 0.04 & 0.82 & 0.04 & 0.83 & 0.04 \\
\hline Cross-country & 0.66 & 0.20 & 0.56 & 0.23 & 0.63 & 0.16 & 0.70 & 0.09 & 0.61 & 0.24 & 0.63 & 0.21 & 0.66 & 0.17 \\
\hline \multirow[t]{2}{*}{ Country } & \multicolumn{2}{|c|}{$\begin{array}{l}\text { Personal } \\
(\beta=-1)\end{array}$} & \multicolumn{3}{|c|}{$\begin{array}{l}\text { Personal } \\
(\beta=0)\end{array}$} & \multicolumn{2}{|c|}{$\begin{array}{l}\text { Personal } \\
(\beta=1)\end{array}$} & \multicolumn{2}{|c|}{$\begin{array}{l}\text { Community } \\
(\beta=-1)\end{array}$} & \multicolumn{3}{|c|}{$\begin{array}{l}\text { Community } \\
(\beta=0)\end{array}$} & \multicolumn{2}{|c|}{$\begin{array}{l}\text { Community } \\
(\beta=1)\end{array}$} \\
\hline & $\mathrm{Av}$ & Gini & Av & & Gini & Av & Gini & $\mathrm{Av}$ & Gin & Av & & Gini & Av & Gini \\
\hline Austria & 0.82 & 0.01 & & & 0.01 & 0.82 & 0.01 & 0.63 & 0.08 & 8 & & 0.06 & 0.70 & 0.05 \\
\hline Belgium & 0.79 & 0.04 & 0. & 79 & 0.04 & 0.79 & 0.04 & 0.51 & 0.06 & 0.5 & 56 & 0.05 & 0.63 & 0.03 \\
\hline Czech Rep. & 0.70 & 0.06 & 0. & 73 & 0.05 & 0.76 & 0.04 & 0.33 & 0.21 & 0.3 & 35 & 0.20 & 0.40 & 0.10 \\
\hline Denmark & 0.75 & 0.02 & 0. & 76 & 0.02 & 0.77 & 0.02 & 0.85 & 0.04 & 0.8 & 86 & 0.03 & 0.87 & 0.03 \\
\hline Estonia & 0.65 & 0.10 & 0. & 70 & 0.08 & 0.74 & 0.06 & 0.07 & 0.87 & 0.1 & 12 & 0.59 & 0.47 & 0.10 \\
\hline Finland & 0.87 & 0.01 & 0.8 & 87 & 0.01 & 0.88 & 0.01 & 0.76 & 0.03 & 0.7 & 78 & 0.02 & 0.81 & 0.01 \\
\hline France & 0.82 & 0.03 & 0.8 & 83 & 0.03 & 0.83 & 0.03 & 0.72 & 0.09 & 0.7 & 74 & 0.08 & 0.75 & 0.07 \\
\hline Germany & 0.84 & 0.02 & 0.8 & 85 & 0.02 & 0.85 & 0.01 & 0.63 & 0.02 & 0.6 & 65 & 0.02 & 0.67 & 0.03 \\
\hline Greece & 0.66 & 0.08 & 0. & 67 & 0.07 & 0.69 & 0.06 & 0.12 & 0.68 & 0.1 & 14 & 0.54 & 0.38 & 0.06 \\
\hline Hungary & 0.48 & 0.13 & 0. & 56 & 0.09 & 0.64 & 0.06 & 0.44 & 0.05 & 0.4 & 45 & 0.05 & 0.47 & 0.06 \\
\hline Iceland & 0.75 & 0.06 & 0. & 78 & 0.04 & 0.81 & 0.03 & 0.95 & 0.01 & 0.9 & 95 & 0.01 & 0.95 & 0.01 \\
\hline Ireland & 0.79 & 0.02 & 0. & 79 & 0.02 & 0.79 & 0.02 & 0.63 & 0.02 & 0.6 & 66 & 0.02 & 0.69 & 0.01 \\
\hline Italy & 0.65 & 0.07 & 0. & 68 & 0.06 & 0.71 & 0.05 & 0.44 & 0.40 & 0.4 & 49 & 0.33 & 0.66 & 0.10 \\
\hline Netherlands & 0.80 & 0.02 & 0. & 81 & 0.01 & 0.83 & 0.01 & 0.67 & 0.06 & 0.6 & 69 & 0.05 & 0.71 & 0.05 \\
\hline
\end{tabular}


Table 4 (continued)

\begin{tabular}{|c|c|c|c|c|c|c|c|c|c|c|c|c|}
\hline \multirow[t]{2}{*}{ Country } & \multicolumn{2}{|c|}{$\begin{array}{l}\text { Personal } \\
(\beta=-1)\end{array}$} & \multicolumn{2}{|c|}{$\begin{array}{l}\text { Personal } \\
(\beta=0)\end{array}$} & \multicolumn{2}{|c|}{$\begin{array}{l}\text { Personal } \\
(\beta=1)\end{array}$} & \multicolumn{2}{|c|}{$\begin{array}{l}\text { Community } \\
(\beta=-1)\end{array}$} & \multicolumn{2}{|c|}{$\begin{array}{l}\text { Community } \\
(\beta=0)\end{array}$} & \multicolumn{2}{|c|}{$\begin{array}{l}\text { Community } \\
(\beta=1)\end{array}$} \\
\hline & $\mathrm{Av}$ & Gini & $\mathrm{Av}$ & Gini & $\mathrm{Av}$ & Gini & $\mathrm{Av}$ & Gini & $\mathrm{Av}$ & Gini & $\mathrm{Av}$ & Gini \\
\hline Norway & 0.85 & 0.03 & 0.85 & 0.03 & 0.86 & 0.03 & 0.87 & 0.03 & 0.87 & 0.03 & 0.88 & 0.03 \\
\hline Poland & 0.64 & 0.06 & 0.68 & 0.05 & 0.72 & 0.03 & 0.23 & 0.28 & 0.28 & 0.20 & 0.37 & 0.11 \\
\hline Portugal & 0.06 & 0.59 & 0.17 & 0.32 & 0.45 & 0.05 & 0.40 & 0.20 & 0.48 & 0.14 & 0.59 & 0.07 \\
\hline Slovak Rep. & 0.59 & 0.04 & 0.65 & 0.03 & 0.71 & 0.02 & 0.03 & 0.88 & 0.06 & 0.46 & 0.35 & 0.03 \\
\hline Slovenia & 0.80 & 0.04 & 0.80 & 0.04 & 0.81 & 0.03 & 0.28 & 0.11 & 0.33 & 0.05 & 0.38 & 0.00 \\
\hline Spain & 0.56 & 0.15 & 0.63 & 0.11 & 0.69 & 0.07 & 0.73 & 0.04 & 0.75 & 0.04 & 0.77 & 0.03 \\
\hline Sweden & 0.87 & 0.02 & 0.87 & 0.02 & 0.87 & 0.02 & 0.89 & 0.03 & 0.89 & 0.03 & 0.90 & 0.03 \\
\hline Switzerland & 0.90 & 0.02 & 0.90 & 0.02 & 0.90 & 0.02 & 0.19 & 0.20 & 0.32 & 0.09 & 0.49 & 0.03 \\
\hline UK & 0.83 & 0.04 & 0.83 & 0.04 & 0.84 & 0.04 & 0.65 & 0.04 & 0.67 & 0.04 & 0.69 & 0.04 \\
\hline Cross-country & 0.73 & 0.10 & 0.75 & 0.08 & 0.78 & 0.05 & 0.57 & 0.18 & 0.60 & 0.16 & 0.65 & 0.11 \\
\hline
\end{tabular}

Av and Gini represent the average achievement and within-country Gini coefficient in a given country (given in row) for a given measure of well-being (given in column), respectively. The last row represents the average achievement and cross-country Gini coefficient in a given measure of well-being

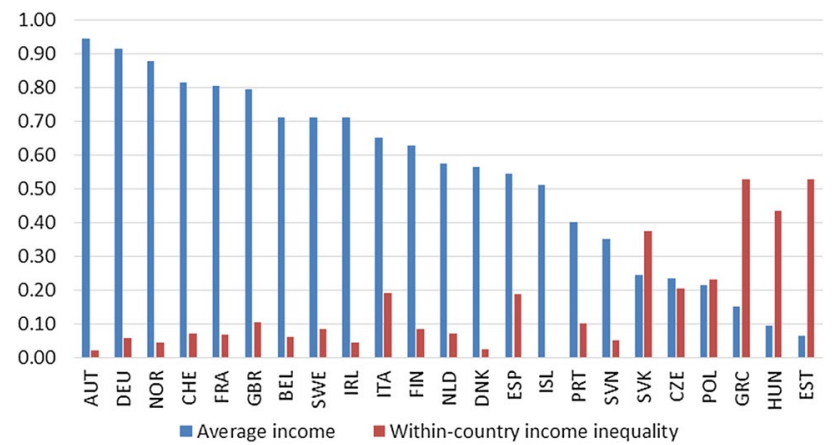

Fig. 1 The association between average income and within-country income inequality

perfect substitutes (i.e., $\beta=1$ ) or have some degree of complementarity between them (i.e., $\beta \leq 0$ ). In this subsection, we analyzed the average achievement scores and within- and cross-country inequality in different multidimensional well-being categories. In the next subsection, we analyze the sensitivity of composite scores and rankings to the choice of $\beta$ parameters.

\subsection{Regional Composite Well-Being Scores and Rankings}

In this subsection, we analyze composite well-being scores and rankings of European regions in each well-being category when different $\beta$ parameters are used in the aggregation procedure. In particular, we will examine how sensitive composite scores and rankings are to the choice of $\beta$ parameter (i.e., how composite scores and rankings vary when dimensions are considered to be perfect substitutes or complements). 
First of all, we examine the rank correlation coefficients when multidimensional wellbeing composite indices are obtained with different $\beta$ parameters in $2014 .{ }^{30} \mathrm{We}$ find that the composite well-being index rankings are positively and significantly correlated with each other even though we allow the dimensions to be perfect complements or complementary at some degree. In the lines with the literature that analyzed the redundancy of composite indices, one might argue that the composite well-being indices obtained with alternative $\beta$ parameters are redundant and an index with a single $\beta$ parameter would be sufficient to rank regions since the rankings are positively and significantly correlated with each other. However, we argue that even though rankings are highly and positively correlated with each other when different $\beta$ parameters are used, they convey distinctively different outcomes for two reasons. First, rankings obtained with different $\beta$ parameters can be very similar, but they produce very different multidimensional well-being scores, within- and cross-country inequality measures. For instance, depending on whether wellbeing dimensions are considered to be perfect substitutes or complements at some degree, composite well-being scores and inequality measures do vary dramatically (see Table 4 for average multidimensional well-being scores in different categories, and within- and cross-country inequality measures with different $\beta$ parameters). When well-being dimensions are considered as perfect substitutes (complements at some degree), there is a lower (higher) within- and cross-country inequality and higher (lower) multidimensional wellbeing across the European regions. As some of the most important goals and policy decisions of the EU are based on tracking the multidimensional well-being (e.g., the European Commission's "Going beyond GDP” initiative) and decreasing regional inequality (e.g., the main objective of the EU structural funds is to reduce the income inequality), composite indices that are obtained with different $\beta$ parameters gives distinctively different signals to policymakers.

The plots in Fig. 2 compare overall, material, personal and community well-being scores obtained when the sub-dimensions are considered as perfect substitutes (i.e., when $\beta=1$ or arithmetic mean of dimensions) with the composite well-being scores obtained when the sub-dimensions are considered as complements at some degree (i.e., when $\beta=-1$ ). This figure clearly shows that there is a major variation in composite scores achieved by the most European regions when different $\beta$ parameters are used. It can be seen in this figure that regions that achieved a higher composite score (i.e., high performers) are located close to the 45-line degree which suggests that their composite scores in different well-being categories are less sensitive to the choice of $\beta$ parameter. These regions have relatively balanced achievements across the sub-dimensions. On the other hand, composite scores of regions with unbalanced achievements across the sub-dimensions are more sensitive to the choice of $\beta$ parameter and these regions are the ones that are located far away from the 45 -line degree. For instance, Table 5 presents some regions whose composite scores are extremely sensitive to the choice of $\beta$ parameter and that these regions would have had very different overall, personal, material, and community well-being scores when the dimensions are considered as perfect substitutes $(\beta=1)$ or complements at some degree $(\beta=-1)$. The variation in composite scores for these regions are quite high when $\beta$ increased from -1 to +1 . For instance, overall well-being score of Lombardy would have been 0.692 lower if one were consider dimensions to be complements at some degree (i.e., $\beta=-1$ ) rather than them being perfect substitutes (i.e., $\beta=1$ ). Most of these regions that see major

\footnotetext{
30 The lowest correlation coefficient between composite indices obtained with alternative $\beta$ parameters is 0.84 .
} 
changes in their composite well-being scores when two different $\beta$ parameters used are located at the southern Europe (e.g., regions of Italy, Spain, Greece, and Portugal) and eastern Europe (e.g., regions of Estonia, Czech Republic, and Hungary). Common characteristic of these regions is that they have relatively unbalanced performances in sub-dimensions. In one hand (when $\beta=1$ ), relatively poor performances in some sub-dimensions are compensated by good performances in other sub-dimensions and on the other hand (when $\beta=-1$, poor performances in some sub-dimensions are reflected in lower composite wellbeing scores. $^{31}$

We furthermore show that there are major rank reversals when different $\beta$ parameters are used to obtain composite scores even though the rankings obtained with different $\beta$ parameters are positively and significantly correlated with each other. ${ }^{32}$ The plots in Fig. 3 compare overall, material, personal and community composite well-being ranks in 2014 when $\beta$ is set to -1 and +1 . This figure reveals that the high performing regions are less sensitive to the choice of $\beta$ parameter as they are located near the 45 -line degree. On the other hand, rankings of some regions are extremely sensitive to the choice of $\beta$ parameter as they are far off from the 45-line degree. For instance, some regions are ranked higher when sub-dimensions are considered as complements (i.e., plots that are located at the upper left of the 45-line degree) and some others are ranked in relatively higher positions if one were to consider sub-dimensions as substitutes of each other (i.e., plots that are located at the lower right of the 45-line degree). Table 6 provides some of the regions that would experience major rank reversals in composite well-being indices when $\beta=1$ and $\beta=-1$ are used to obtain composite well-being indices. Panel A (B) of Table 6 represents some set of regions that would have been ranked in higher positions when sub-dimensions are considered to be complements at some degree (perfect substitutes) compared to the case when the dimensions are considered as perfect substitutes (complement at some degree). For instance, Zurich and Aland rank at the 88th and 39th positions based on their overall well-being achievement when the dimensions are considered to be perfect substitutes (i.e., when $\beta=1$ ), whereas, these two regions would have been ranked at the 155th and 102nd positions when dimensions are more seen as complements (i.e., $\beta=-1$ ), respectively. The reason why these regions rank in lower positions when $\beta=-1$ is used to obtain overall well-being index is that their achievements in civic engagement dimension are relatively low. On the other hand, East Macedonia of Greece ranks at the 177th (213th) position when $\beta=-1(\beta=1)$ is used to obtain overall well-being score. Even though East Macedonia region of Greece have low achievements in some well-being dimensions, neither of its achievements in well-being dimensions are at the lowest possible levels allowing this region to achieve relatively higher position when dimensions are considered to be complements. Most of the regions that East Macedonia region of Greece surpass when the dimensions have some complementarity are the ones that have the lowest achievement score in one or more dimensions moving them to lower ranking positions when dimensions are considered as complements. Similar patterns are observed for the remaining set of regions

\footnotetext{
31 See Table 2 of supplementary material for the detailed overall, material, personal, and community wellbeing composite indices and absolute change in composite scores when different $\beta$ parameters are used to obtain the composite indices.

32 See Table 3 of supplementary material for the detailed rankings of European regions based on their achievements in overall, material, personal and community well-being composite indices when different $\beta$ parameters are used to obtain the composite indices.
} 

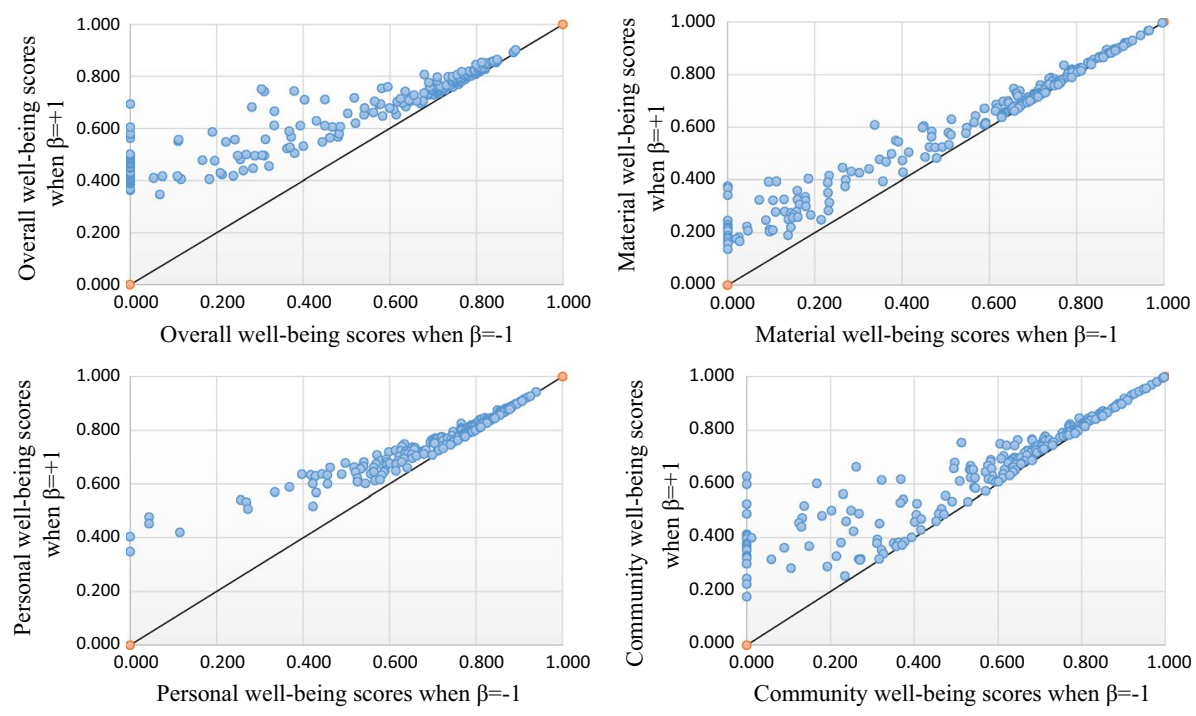

Fig. 2 Scatter plots of overall, material, personal and community composite well-being scores in 2014 when $\beta=-1$ and $\beta=+1$

that moved to higher positions when dimensions are seen more of complements compared to the case where they are considered to be perfect substitutes.

Overall, even though the rankings are positively and significantly correlated with each other, there are also major differences between two rankings when the dimensions are more seen as substitutes or complements, respectively (i.e., $\beta=1$ and $\beta=-1$, respectively). Regions that have relatively balanced (unbalanced) achievements between the dimensions move to higher rankings when dimensions are considered to be complementary (perfect substitutes).

\subsection{Over-Time Changes in Multidimensional Well-Being and Inequality}

In the previous sections, we analyzed the multidimensional well-being and inequality across the European regions depending on the $\beta$ parameter choice and in this subsection, we will examine the well-being improvements and changes in inequality measures between 2000 and 2014. ${ }^{33}$ Table 7 offers average achievement and inequality measures in income dimension and composite indices in 2000 and 2014 when different $\beta$ parameters are used to aggregate dimensions. Panel A of Table 7 offers the average achievement in income and composite well-being outcomes and multidimensional inequality (i.e., Gini measures) in 2000 and 2014 for 103 regions that have overlapping information for all well-being dimensions in both years. Whereas, Panel B of Table 7 offers the same information for different number of regions where we have information for all dimensions that are used each respective composite well-being category, respectively.

\footnotetext{
${ }^{33}$ It should be noted that we only used the regions that have overlapping information for the dimensions used for each multidimensional well-being category to examine the changes in multidimensional well-being and inequality.
} 


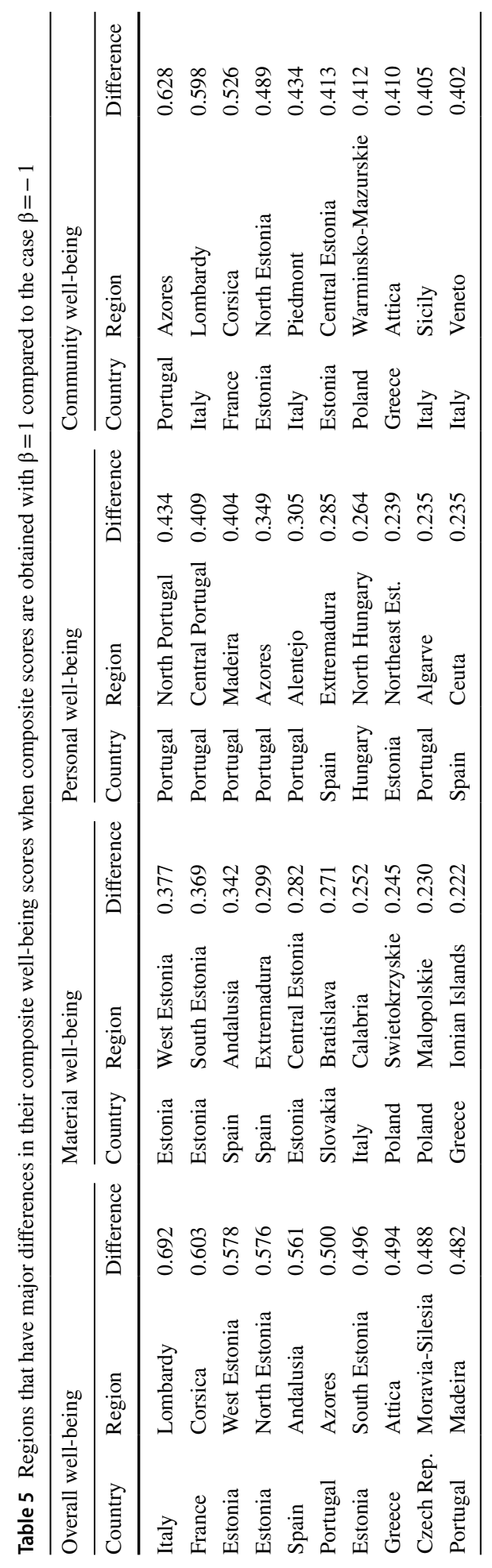



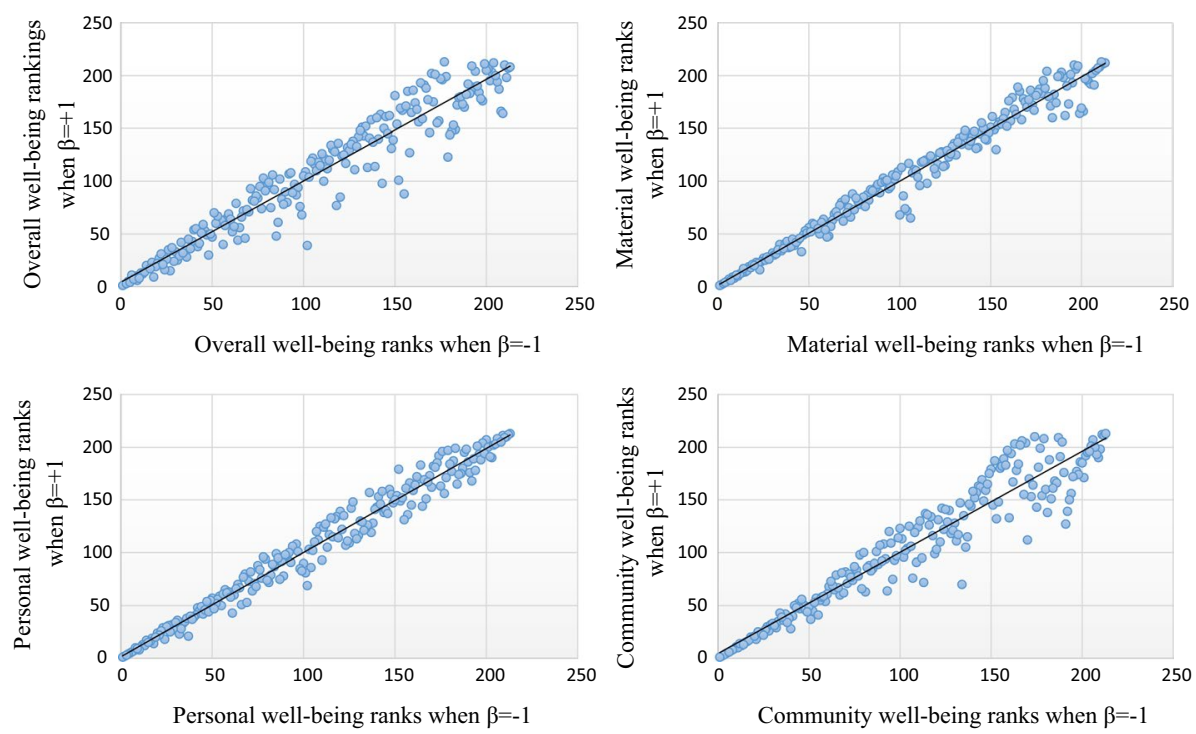

Fig. 3 Scatter plots of overall, material, personal and community composite well-being ranks in 2014 when $\beta=-1$ and $\beta=+1$

Since both panels of Table offer roughly similar outcomes, we discuss the results from the panel $A$ of Table 7 . Irrespective of the $\beta$ measure, average overall well-being index increased and multidimensional inequality across the European regions are decreased between 2000 and 2014. However, the increase in average overall well-being index is relatively higher when dimensions are considered to have some degree of complementarity compared to the case when dimensions are perfect substitutes (e.g., average overall well-being index increased by $0.206,0.202$, and 0.165 between 2000 and 2014 when $\beta$ is set to be $-1,0$, and 1 , respectively). This suggests that the improvements in well-being dimensions across the European regions between 2000 and 2014 were towards rounded achievements across well-being dimensions. Similarly, Gini coefficients in 2014 were smaller than the ones in 2000 suggesting that the inequality in overall well-being across European regions declined between 2000 and 2014. Similarly, decrease in Gini coefficient is relatively higher when dimensions are considered to have some complementarity (i.e., $\beta \leq 0$ ). When we move to composite well-being categories, average achievement and inequality levels in material well-being across the European regions roughly remained to be the same irrespective of the $\beta$ parameter choice. ${ }^{34}$ The composite well-being category in which European regions experienced the largest improvement during the period is personal well-being one. Average achievement in this category roughly doubled between 2000 and 2014, and there is distinctive decrease in inequality measures when well-being dimensions are considered to have some degree of complementarity (i.e., Gini coefficients dropped from 0.423 and 0.377 to 0.165 and 0.130 when $\beta$ is set to -1 and 0 , respectively). This

\footnotetext{
34 To be precise, there is a small increase in material well-being category (this increase ranges between 0.025 and 0.038 depending $\beta$ parameter choice), but this increase is minimal considering the comparison period (i.e., between 2000 and 2014). Similarly, there is also a slight increase in inequality measures when dimensions are treated as complements.
} 


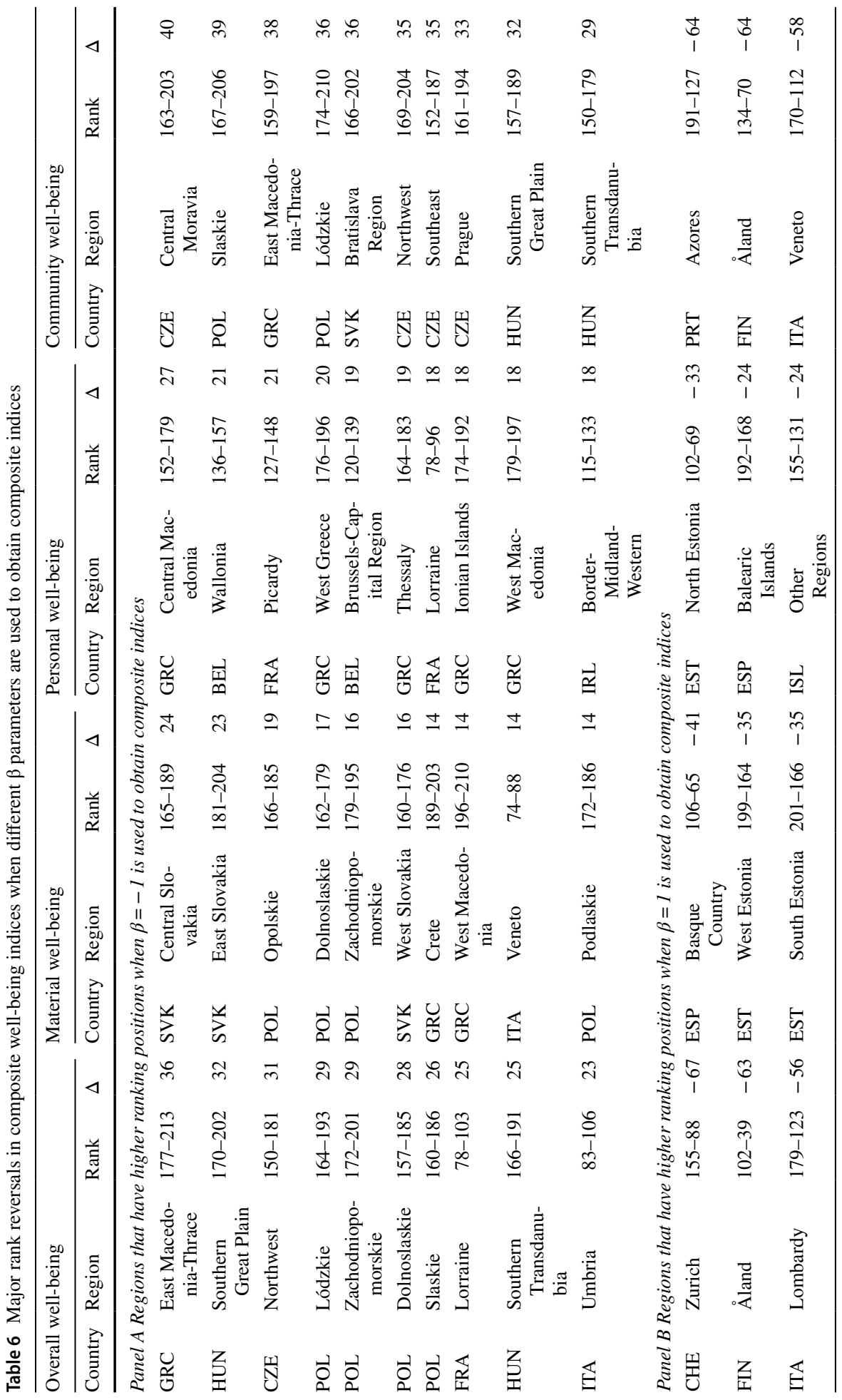




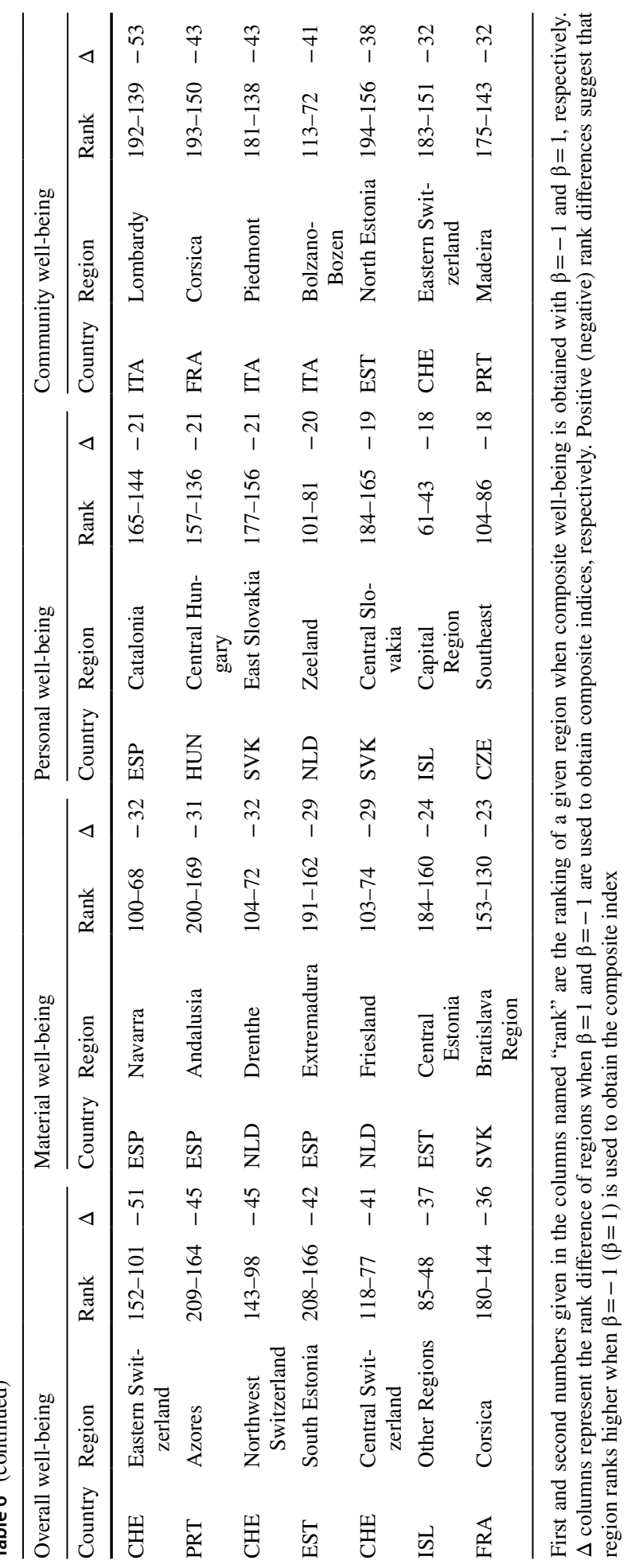


Table 7 Average achievement in composite well-being outcomes and inequality measures in 2000 and 2014

\begin{tabular}{|c|c|c|c|c|c|c|c|}
\hline & \multicolumn{2}{|c|}{$\beta=-1$} & \multicolumn{2}{|l|}{$\beta=0$} & \multicolumn{2}{|l|}{$\beta=1$} & \multirow[t]{2}{*}{ No regions } \\
\hline & Mean & Gini & Mean & Gini & Mean & Gini & \\
\hline \multicolumn{8}{|c|}{$\begin{array}{l}\text { Panel A Composite well-being and inequality measures for } 103 \\
\text { regions }\end{array}$} \\
\hline \multicolumn{8}{|c|}{ Overall } \\
\hline 2014 & 0.527 & 0.296 & 0.597 & 0.204 & 0.679 & 0.111 & 103 \\
\hline 2000 & 0.321 & 0.437 & 0.396 & 0.309 & 0.514 & 0.145 & 103 \\
\hline \multicolumn{8}{|c|}{ Material } \\
\hline 2014 & 0.548 & 0.295 & 0.575 & 0.262 & 0.624 & 0.197 & 103 \\
\hline 2010 & 0.523 & 0.279 & 0.547 & 0.253 & 0.586 & 0.202 & 103 \\
\hline \multicolumn{8}{|c|}{ Personal } \\
\hline 2014 & 0.681 & 0.165 & 0.713 & 0.130 & 0.753 & 0.087 & 103 \\
\hline 2010 & 0.307 & 0.423 & 0.331 & 0.377 & 0.423 & 0.182 & 103 \\
\hline \multicolumn{8}{|c|}{ Community } \\
\hline 2014 & 0.587 & 0.198 & 0.611 & 0.181 & 0.660 & 0.126 & 103 \\
\hline 2010 & 0.443 & 0.284 & 0.474 & 0.250 & 0.533 & 0.177 & 103 \\
\hline \multicolumn{8}{|l|}{ Income } \\
\hline 2014 & 0.582 & 0.276 & & & & & 103 \\
\hline 2010 & 0.488 & 0.308 & & & & & 103 \\
\hline \multicolumn{8}{|c|}{$\begin{array}{l}\text { Panel B Composite well-being and inequality for different number } \\
\text { of regions }\end{array}$} \\
\hline \multicolumn{8}{|l|}{ Overall } \\
\hline 2014 & 0.658 & 0.219 & 0.677 & 0.198 & 0.707 & 0.161 & 145 \\
\hline 2010 & 0.587 & 0.209 & 0.605 & 0.192 & 0.631 & 0.162 & 145 \\
\hline \multicolumn{8}{|c|}{ Personal } \\
\hline 2014 & 0.721 & 0.124 & 0.745 & 0.101 & 0.774 & 0.073 & 159 \\
\hline 2010 & 0.322 & 0.375 & 0.354 & 0.326 & 0.439 & 0.167 & 159 \\
\hline \multicolumn{8}{|c|}{ Community } \\
\hline 2014 & 0.553 & 0.255 & 0.584 & 0.221 & 0.649 & 0.141 & 197 \\
\hline 2010 & 0.383 & 0.384 & 0.414 & 0.347 & 0.505 & 0.223 & 197 \\
\hline \multicolumn{8}{|l|}{ Income } \\
\hline 2014 & 0.689 & 0.205 & & & & & 183 \\
\hline 2010 & 0.608 & 0.236 & & & & & 183 \\
\hline
\end{tabular}

Mean columns represent the average achievement scores in respective well-being index and income dimension. Gini coefficients measure the inequality in these well-being categories and income dimension

suggests that well-being improvements in this category across the European regions were towards rounded achievements across the well-being dimensions in this category (i.e., health, education, access to services). Community well-being index also improved between 2000 and 2014, and these improvements were roughly similar irrespective of the $\beta$ parameter choice (i.e., average improvements in community composite index were $0.143,0.137$, and 0.128 when $\beta$ is equal to $-1,0$, and 1 , respectively). Finally, average achievement in income dimension increased from 0.488 to 0.582 and the Gini coefficient dropped from 0.308 to 0.276 between 2000 and 2014, respectively. Comparing income dimension with other composite well-being indices, we observe that improvements in overall, personal and 


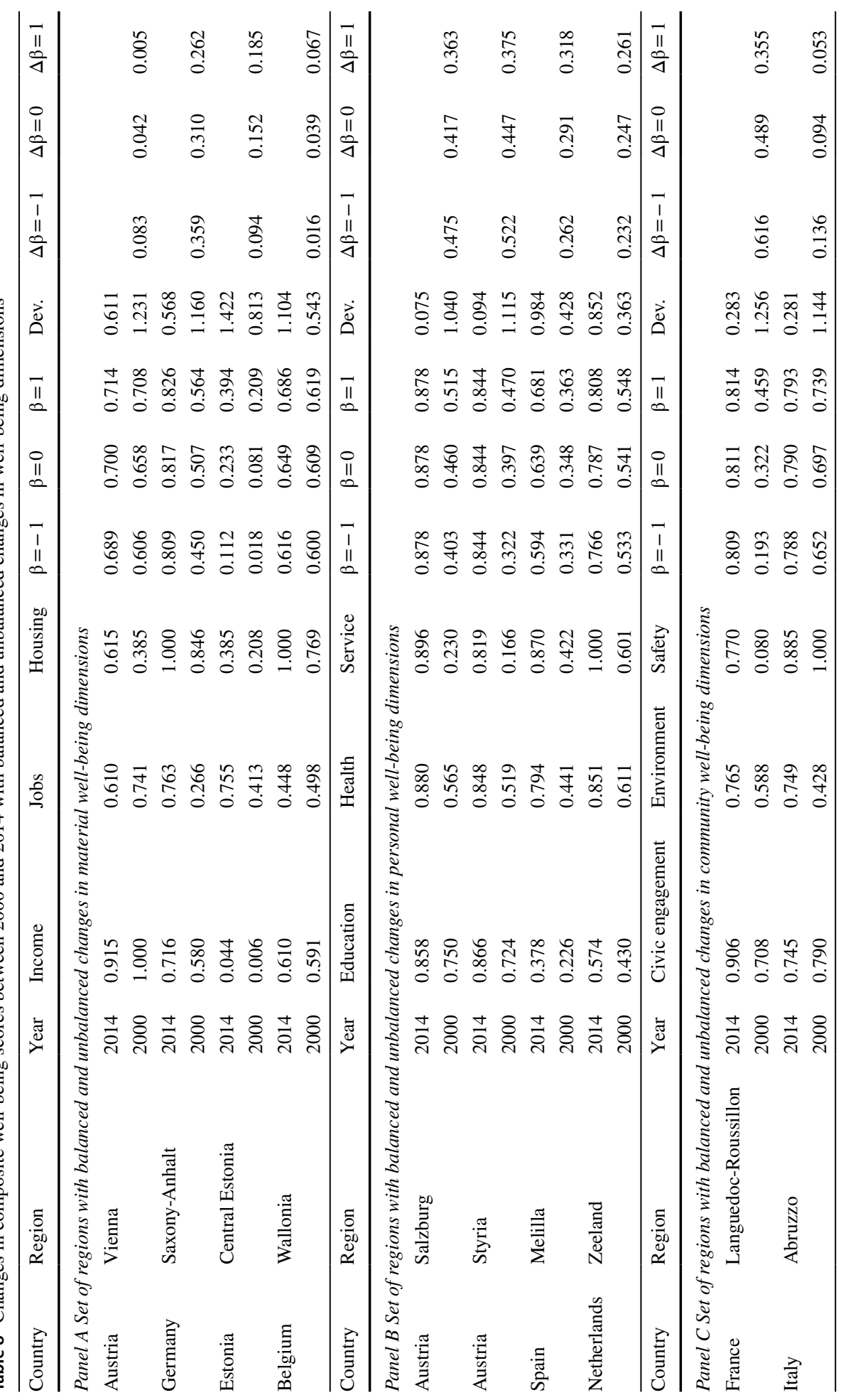




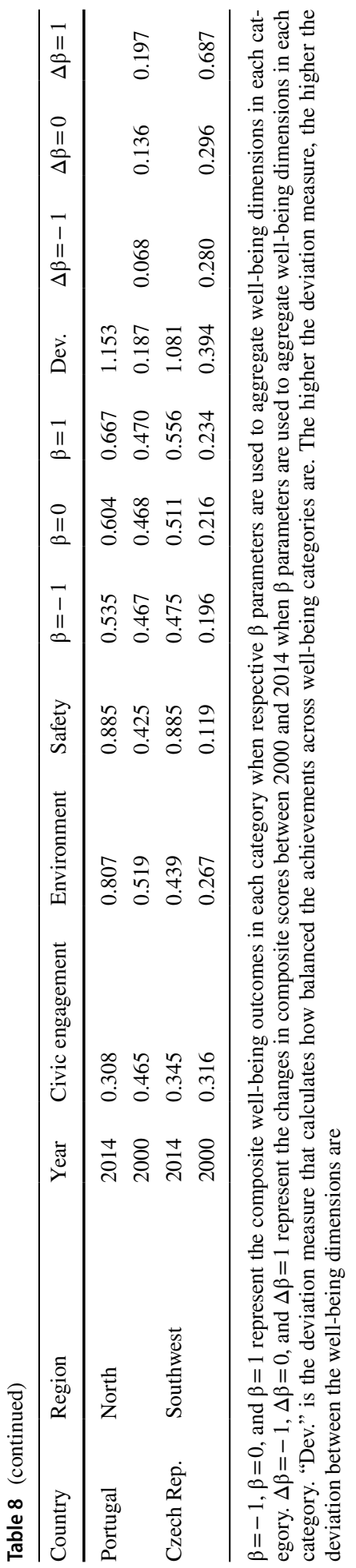


community well-being categories between 2000 and 2014 were higher than the improvement in the income dimension over the same period irrespective of the $\beta$ parameter choice. Similarly, decreases in overall, personal, and community well-being inequality were relatively higher than the decrease in income inequality between 2000 and 2014. On the other hand, achievements in material well-being (which also includes income dimension) is higher than income dimension when well-being dimensions are considered to be perfect substitutes (i.e., $\beta=1$ ). Overall, given the changes in composite well-being categories and income dimension, we can suggest that multidimensional well-being improvements were relatively higher compared to the improvements in income dimension, which also led to a lower degree of multidimensional inequality across the European regions.

To analyze the effects of $\beta$ parameter choice on the changes in the regional well-being outcomes, Panels A, B, and C of Table 8 offer achievements of some regions in well-being dimensions in material, personal, community categories, and composite well-being outcomes with different $\beta$ parameters in 2000 and 2014, respectively. Each panel consists of two regions that experienced changes in well-being outcomes that were towards balanced (uneven) composition of development across the well-being dimensions. ${ }^{35}$ Furthermore, to assess whether the changes in well-being achievements between 2000 and 2014 were towards balanced (uneven) composition of development across the well-being dimensions, we obtain a "deviation" measure which calculates the level of evenness of achievements across well-being categories. ${ }^{36}$ The lower (higher) this score, the more rounded (unbalanced) the achievements across the well-being dimensions in each category are.

Panel A of Table 8 offers two regions that experienced changes in income, jobs and housing dimensions that were towards balanced (unbalanced) achievements across the well-being dimensions in material well-being category. Standard of living and job conditions (income and jobs dimensions) in Vienna deteriorated between 2000 and 2014 but the region experienced major improvement in housing, which led to a more rounded composition of development in this category (e.g., "deviation" measure dropped from 1.23 to 0.61 between 2000 and 2014). Even though the aggregate improvement across the three dimensions is limited (i.e., aggregate change in achievements in the three dimensions was 0.015), achievements across the dimensions were more rounded in 2014 than in 2000, which can also be seen by looking at the changes in composite scores when $\beta=0$ and $\beta=-1$ are used in the aggregation (i.e., composite index outcomes for Vienna increased by 0.042 and 0.083 when respective $\beta$ parameters are used). Similar case is observed for Saxony-Anhalt region of Germany. This region experienced improvements in all dimensions, however, the major improvement had been in the dimension that was the least achieved one in 2000 (i.e., jobs dimension). Improvements in this region were towards rounded achievements across the three dimensions, which are also reflected in the composite score improvements when $\beta=0$ and $\beta=-1$ are used in aggregation since the changes in composite scores are higher than the change in the index that is obtained with arithmetic mean. On the other hand, over-time improvements in central Estonia and Wallonia region of Belgium were towards unrounded

\footnotetext{
35 In this comparison, we only report some regions for illustrative reasons; however, detailed comparisons for all regions are available from author upon request.

36 This measure is obtained by sum of absolute deviation across the well-being dimensions in a given wellbeing category. In particular, since each well-being category has three well-being dimensions, this measure is obtained by lachievement in dimension 1 - achievement in dimension $21+$ lachievement in dimension 1 - achievement in dimension $3 \mid+$ lachievement in dimension 2-achievement in dimension 3|. "Deviation" measure would be zero if achievements across the three well-being dimensions are equal, suggesting that the achievements in well-being dimensions are fully rounded.
} 
achievements across the three dimensions. Wallonia region experienced a deterioration in jobs dimension (which was the least achieved dimension in 2000) and an improvement in housing dimension (which was the most achieved dimension in 2000), which led to a divergence in achievements across the well-being dimensions (i.e., deviation measure increased by 0.56 between 2000 and 2014). Whereas, even though there had been an improvement in all dimensions in the central Estonia, the major increase was observed in jobs dimension (which was the highest achieved dimension in 2000). Even though, equally-weighted index (i.e., when $\beta=1$ ) does not differentiate whether the improvements were towards even (unbalanced) composition of development across the three dimensions, improvements in composite scores are relatively lower when dimensions allowed to have some degree of complementarity (i.e., when composite indices are obtained with $\beta=0$ and $\beta=-1$ ). Panels $\mathrm{B}$ and $\mathrm{C}$ of Table 8 also offer two regions that experienced changes in well-being dimensions in personal and community well-being categories that were towards rounded (unbalanced) achievements across the three dimensions, respectively (see respective panels in Table 8 for the details).

Overall, in this section, we showed that the over-time improvements in composite scores are different when dimensions are considered to be complementary at some degree when the over-time changes in achievement levels in dimensions are towards balanced (or unbalanced) composition of development across the dimensions or not. Even (uneven) composition of the development across the dimensions are reflected in the composite indices that are obtained with $\beta \leq 0$ by having relatively higher (lower) changes in composite well-being scores than the changes in the composite index obtained with arithmetic mean. This feature of aggregation is particularly important since the choice of $\beta$ parameter for aggregation (i.e., whether policymakers are sensitive to the even composition of development across the dimensions or not) would lead to different approaches by the regional policymakers to improve regional composite well-being outcomes. For instance, if a composite index is obtained with the arithmetic mean aggregation method (i.e., when $\beta$ is set to be 1 ), regional policymakers can choose to improve any dimension they wish irrespective of whether this dimension is the least or most achieved dimension. In this case, regions may choose to improve "easy" dimensions (i.e., well-being dimensions that are relatively easier to improve or less costly to manipulate) since any aggregate improvement in these dimensions would be reflected similarly in the composite score irrespective of whether this dimension is the least or most achieved one. However, if aggregation procedure prioritizes balanced composition of development or penalizes uneven composition of development (i.e., the cases when $\beta \leq 0$ ), regions would prioritize improvements in dimensions in which their achievements are relatively weak since this would lead to a higher improvement in their composite scores (see the cases in Table 8). Therefore, if the aim is to promote balanced composition of development across well-being dimensions, policymakers should integrate this feature in their aggregation procedure to give the right signals to the policymakers.

\section{EU Structural Fund Allocations with Composite Well-Being Indices}

In this section, we evaluate how the EU structural funds would have been distributed if one were to use the composite indices as a criteria to determine the eligible regions rather than the GDP per capita criteria. Before our analysis, let us offer a brief discussion on what the EU structural funds are and how they are distributed. Under the convergence objective of the European Commission, regions are allocated EU structural funds if their GDP per 
capita in purchasing power parties (PPP) is lower than the $75 \%$ of the EU average (European Parliament and Council of the European Union 2013). The idea behind this objective is to improve the standard of living in the eligible regions so that they can catch up with other regions' standard of living. Recent papers found that this is an effective allocation of funds to eliminate income disparities across the EU regions (see e.g., Bosker 2009; Becker et al. 2013). Even though GDP per capita might be a reasonable benchmark, it lacks to capture the well-being in a more holistic way and there are EU policy documents which also consider the inclusion of additional dimensions beyond GDP per capita when determining the allocation of EU structural funds (European Committee of the Regions 2011). Hence, in this section we examine how the composite indices obtained with different $\beta$ parameters would allocate the regional funding if one were to use them to determine the eligible regions. In other words, if the European Commission were to use composite indices to choose regions that are eligible for the EU structural funds, would the composite indices that are obtained with different $\beta$ parameters allocate funds different than GDP per capita criteria?

To be consistent with the EU structural fund allocation, we only consider 197 regions that are part of the EU for this evaluation. ${ }^{37}$ Table 9 offers the EU average achievement levels in income dimension, and overall, material, personal and community well-being composite indices that are obtained with different $\beta$ parameters, and the threshold achievement levels for each case to determine the eligible regions for the EU structural funds (i.e., regions would be eligible for the EU structural funds if their achievement is below the $75 \%$ of the average score in each respective criteria).

Given these thresholds in each respective criteria, Table 10 summarizes the set of regions that are eligible to the EU structural funds in 2014 with the income dimension, and composite indices that are obtained with different $\beta$ parameters (see Table 12 in Appendix for the list of regions that are eligible for the EU structural funds when income and different composite indices are used as criteria to determine the eligible regions). 77 regions with a total population of 129.7 million are eligible to the EU structural funds if income dimension is used as a criteria, more than the number of eligible regions when the composite indices are used as a criteria (irrespective of the $\beta$ parameter choice). On the other hand, if overall well-being index is used as a criteria to determine the eligible regions, 51, 65, and 70 regions are eligible for the funds when $\beta$ parameters are set to 1,0 and -1 , respectively. The reason why less number of regions is eligible for the funds when the dimensions are perfect substitutes is that the perfect substitution between the dimensions (i.e., when composite index is obtained with $\beta=1$ ) produces a more equal distribution of composite achievements across the regions (i.e., see Table 4 for the within- and cross-country multidimensional well-being inequality when different $\beta$ parameters are used to obtain composite indices). Whereas, when some complementarity between dimensions are allowed (i.e., $\beta \leq 0$ ), there are 15 and 19 more regions eligible for the EU structural funds compared to the case when dimensions are perfect substitutes (i.e., $\beta=1$ ). The difference in the number of eligible regions when different $\beta$ parameters are used to obtain composite indices

\footnotetext{
37 For EU structural fund allocation, we only consider the regions from the countries that are part of the EU and exclude the regions from our analysis that are not part of the EU (i.e., regions of Iceland, Norway, and Switzerland). One should also note that we do not have any data for regional well-being dimensions for the regions of seven countries, which are part of the EU (Bulgaria, Croatia, Cyprus, Latvia, Lithuania, Malta, and Romania). Hence, this analysis should be seen as an illustrative example on how $\beta$ parameter choice in the aggregation procedure could have an effect on policy decisions.
} 
highlights the importance of $\beta$ parameter choice for the EU regional policy if they were to use composite indices to allocate the EU structural funds.

When we move to the sub-composite indices (i.e., material, personal and community composite indices), the number of eligible regions with the material well-being does not differ much from those funded with income dimension irrespective of the $\beta$ parameter. This outcome was expected since the income dimension not only belongs to the material wellbeing category but also it is significantly and positively correlated with other dimensions in the material well-being category (i.e., jobs and housing dimensions). Yet, the number of eligible regions with material well-being slightly differs from those funded with income dimension. For instance, 10 regions that are eligible for the funds with income dimension would not have been eligible for the funds if the material well-being composite index is used to determine eligible regions (see the row in Table 10 that gives the details about the number of regions that are eligible for the funds with income dimension but not with the composite index). On the other hand, the number of eligible regions with the personal well-being criteria would be the least since both within- and cross-country multidimensional inequality is the lowest in this category compared to any other composite well-being (see Table 4 for the details). Yet, the number of eligible regions with the personal wellbeing category differs when composite well-being is obtained with different $\beta$ parameters. For instance, there would be only 11 regions eligible for the funds when composite index obtained with $\beta=1$ and this number increases to 31 when composite index is obtained with $\beta=-1$ highlighting the importance of the choice of $\beta$ parameter when composite indices are used to determine eligible regions. Finally, there are relatively less number of regions that are eligible for funding when community well-being index is used as a criteria compared to income dimension. Similar trend of having more regions eligible for the funds can be seen when the dimensions are seen more complements compared to the case when they are perfect substitutes.

Table 10 also demonstrates that the eligible regions that are identified with the composite indices show some similarity and differences from the ones identified with the income criteria. In one hand, most of the eligible regions that are identified with the composite index criteria are also identified to be eligible regions with the income criteria. In other words, the number of regions that are eligible for funds with the composite index (these number are given at the first row of Table 10) is roughly similar to the number of regions that are eligible for the funds with both income dimension and composite index criteria (see the third row of Table 10 for the details). In the light of the above case, one can suggest that identification of eligible regions for the EU structural funds with income dimension is closely associated with the identification of composite indices. However, there are also distinctive differences between the identified regions when composite indices and income dimension are used as criteria. For instance, there are at least 14, 10, 50, and 25 regions that would have been eligible for the funds if income dimension is used for funding criteria but these regions would not have been eligible for the funds when overall, material, personal and community well-being composite indices are used as criteria (see the seventh row of Table 10 for the detailed set of differences). This is due to the fact that the European regions have relatively equal distributions of achievements in other well-being dimensions compared to the income dimension (see Table 3 for the inequality across the European regions in different well-being dimensions) and an index obtained with the combination of these well-being dimensions identifies less number of regions eligible for the EU structural funds if used as a criteria.

Up to now, we used a threshold values that are relative to the average achievement level of a given criteria to identify the eligible regions for the EU structural funds (i.e., $75 \%$ of 
Table 9 EU average in income dimension and composite indices, and the thresholds for the EU structural funds eligibility

\begin{tabular}{lrll}
\hline Dimension/Index & Beta parameter & EU average & $\begin{array}{l}\text { Threshold levels } \\
\text { (75\% of the EU } \\
\text { average) }\end{array}$ \\
\hline Income dimension & & 0.651 & 0.488 \\
Overall well-being & -1 & 0.563 & 0.422 \\
& 0 & 0.625 & 0.469 \\
Material well-being & 1 & 0.696 & 0.522 \\
& -1 & 0.600 & 0.450 \\
Personal well-being & 0 & 0.622 & 0.466 \\
& 1 & 0.657 & 0.493 \\
& -1 & 0.729 & 0.546 \\
Community well-being & 0 & 0.751 & 0.563 \\
& 1 & 0.777 & 0.583 \\
& 0 & 0.570 & 0.427 \\
& 1 & 0.597 & 0.448 \\
\hline
\end{tabular}

the EU average) since the aim of this fund is to eliminate inequality across the European regions. However, if the aim was to target the most deprived regions, absolute achievement scores would have been more suitable measures for identifying eligible regions. The concept is similar to the relative and absolute measures of poverty [see e.g., Foster (1998), Duclos and Gregoire (2002), Notten and de Neubourg (2011) for detailed discussion] where the former is based on the percentage of a median or mean of a group of population (e.g., $75 \%$ of the mean GDP per capita or the $60 \%$ of the median income), whereas the latter considers a threshold of well-being that is need to sustain basic human needs (e.g., the extreme poverty threshold of $\$ 1.25$ a day). Even though both relative and absolute wellbeing groups could be the same, there might be some regions that are eligible for funds with the relative measure but not eligible with absolute well-being measures or vice versa, which depends on the average achievement level, absolute threshold level and how the well-being is distributed. To provide a complete picture of how well-being outcomes are distributed in each composite well-being and income dimension, we carry out our analysis by looking at the eligible regions when we use the absolute achievement scores as threshold to determine the eligible number of regions and total population that would benefit from these funds.

Table 11 lists the number of regions and total population that would be eligible for funds when different absolute normalized achievement scores with 0.1 increments are used as threshold for determining the eligible regions. ${ }^{38}$ The importance of the $\beta$ parameter choice is more evident with the use of absolute scores as thresholds to determine eligible regions. For instance, if policy makers choose to allocate funds to the most deprived regions by setting the threshold to 0.3 , there would be 50 regions that would be eligible for the funds based on

\footnotetext{
38 Since the highest achievable score in income and respective composite indices is 1 , we use 0.7 as the highest threshold to determine the eligible regions for the funds and consider that the regions that have achievement above 0.7 are relatively well-off regions.
} 


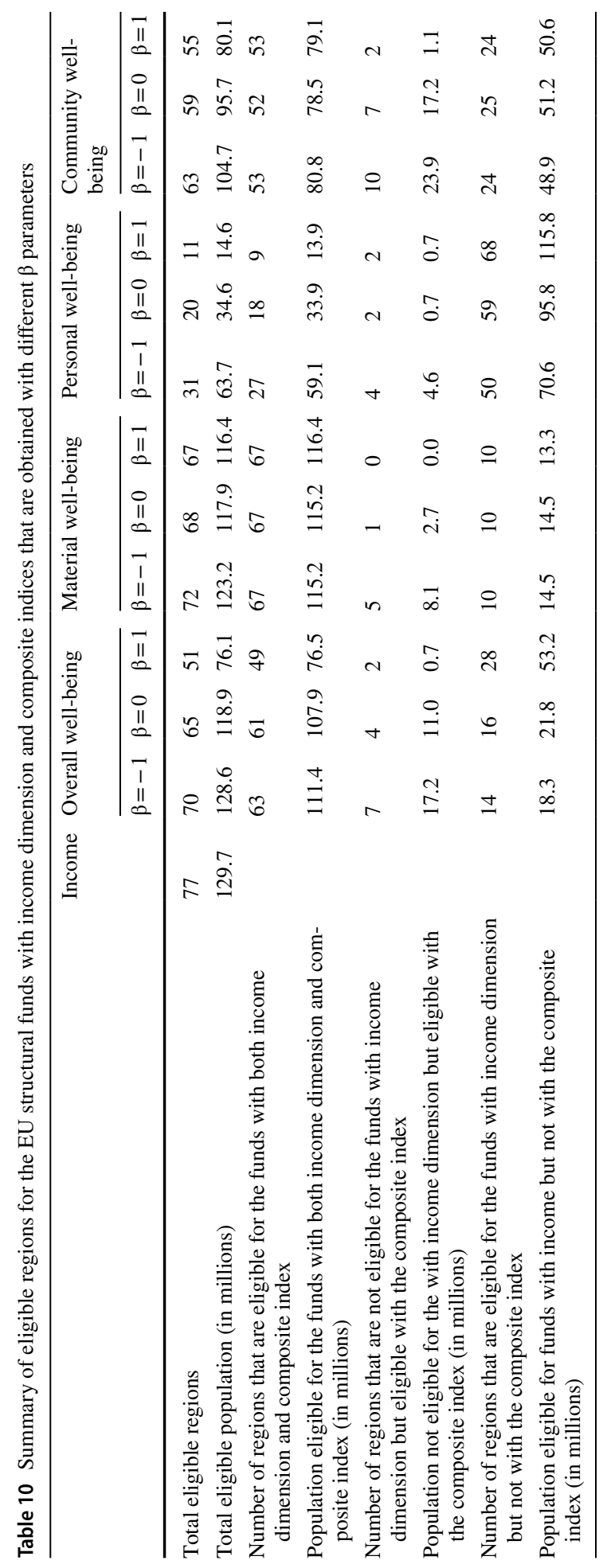




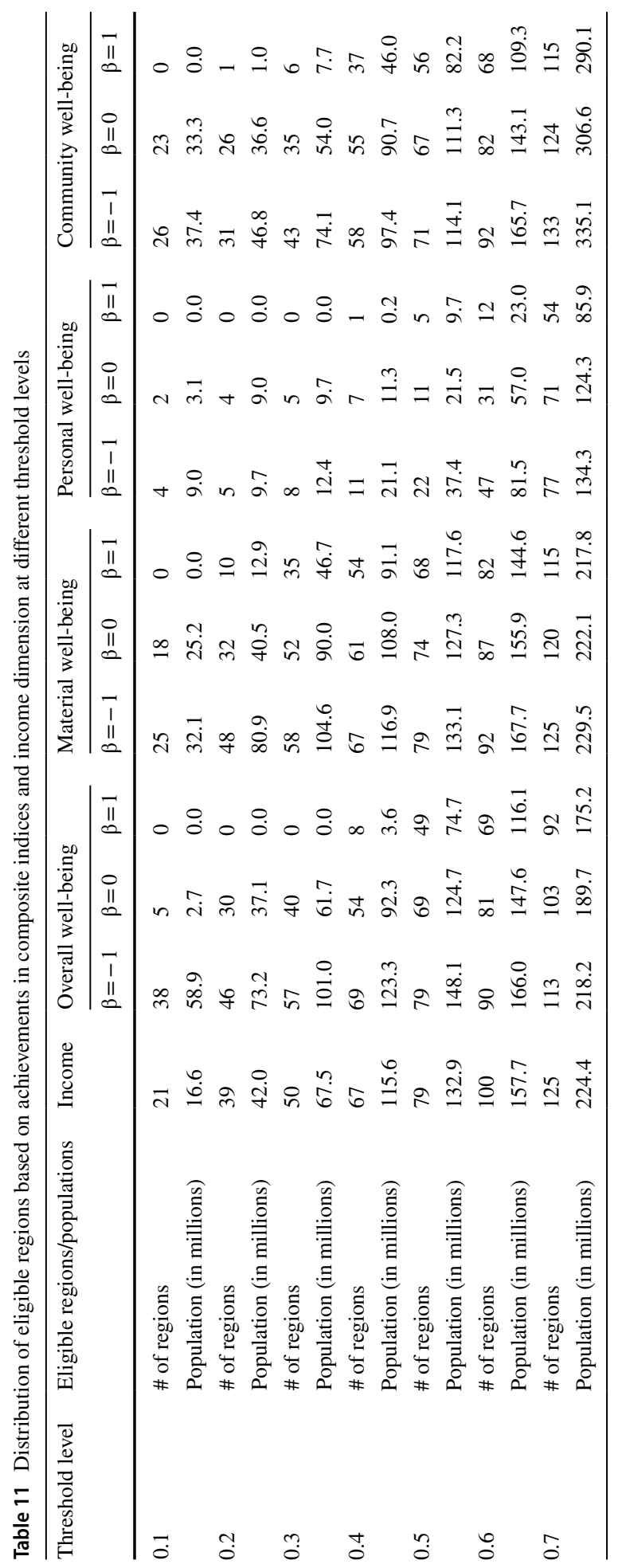


the achievements in income dimension. On the other hand, there would be 57 and 40 regions that would be eligible for funds based on the overall well-being achievements when $\beta$ is set to -1 and 0 , respectively. However, if the dimensions are treated as perfect substitutes, no regions would be qualified for the funds given the 0.3 threshold. Similar trend is seen when absolute achievement levels in material, personal, and community well-being indices are used to determine eligible regions. Furthermore, for all different absolute well-being thresholds, there is always more regions that are eligible for the EU structural funds when we look at the achievements in income dimension compared to the achievements in composite indices when the well-being dimensions are perfect substitutes (i.e., when $\beta=1$ ). ${ }^{39}$ On the other hand, when dimensions are more seen as complements (i.e., when $\beta \leq 0$ ), there are cases where higher number of regions are eligible for funds when we consider the achievements in composite index compared to the one in income dimension. For instance, when $\beta=-1$, more regions are eligible for the funds if one consider the achievements in overall wellbeing index as criteria compared to the achievements in income dimension at all threshold levels up to 0.4. For threshold of 0.5 , similar number of regions is qualified for the funds, but the affected population is higher with the composite index criteria. For threshold of 0.6, more regions are qualified for the funds with income dimension criteria but higher number of people will be affected if the funds are distributed based on composite index criteria (i.e., regions that are eligible with the overall well-being index criteria are relatively more populated). Finally, if one were to use threshold of 0.7, total population that would benefit from these funds and the number of eligible regions are higher with income criteria.

Overall, not only there is a distinctive difference between the number of eligible regions based on the achievements in composite indices and income dimension at different absolute thresholds, but also there are considerable differences in the number of eligible regions based on the choice of $\beta$ parameter when achievements in composite index are used to distribute the funds. Finally, we should also note that the identification of the threshold is also an important criteria when distributing the regional funds. For instance, when we use relative thresholds, there were clearly less number of regions that were eligible for the funds with the composite index criteria compared to the income criteria. However, when we examine the distribution of the achievements in composite scores and income dimension, we have seen that there are more eligible regions for funds based on the achievements in income dimension than the eligible regions based on the composite well-being index outcomes, or vice versa depending on the absolute well-being threshold. Hence, the policymakers should also consider the robustness of the allocation of funds based on different thresholds since distribution of funds might alter based on two different criteria.

\section{Conclusions}

It has been well-accepted that the societal progress should be measured by considering achievements in many well-being dimensions. Furthermore, policymakers emphasized the need for a balanced and sustainable pattern of regional development across well-being dimensions and regions (which is emphasized by the EU policy papers and 2020 goals to

\footnotetext{
39 The identified regions obviously differ with composite indices compared to the income dimension, which are available upon request from the author, yet with income dimension criteria, there are more regions eligible for the funds compared to the eligible regions with the composite index obtained with arithmetic mean.
} 
achieve a balanced and sustainable pattern of territorial development, and adaptation of the geometric mean aggregation of the dimensions of the HDI by the UNDP). In this paper, we take into account these two requirements for measuring multidimensional well-being measurement. We not only aggregate various well-being dimensions to measure the EU regional well-being to go beyond single measure of well-being but also we use generalized mean aggregation procedure to measure whether the well-being achievements in regions have balanced composition of development or not by allowing the dimensions to be more seen as complements.

Our results show that the multidimensional well-being across the European regions are relatively lower when the dimensions are more seen as complements compared to the case when they are considered to be perfect substitutes. Furthermore, there is also a higher multidimensional inequality across the European regions when the dimensions are considered to have some complementarity. Both within- and cross-country multidimensional inequality levels are higher when the dimensions are more seen as complementary due to the fact that regions have unbalanced achievements across the well-being dimensions. In particular, we observe that the Europe consists two clusters of regions that have different composition of development. In one hand, the eastern and southern EU regions (e.g., regions of Estonia, Greece, Slovak Republic, Portugal, Poland, and Italy) have unbalanced composition of development (i.e., achievements across the dimensions are unevenly distributed) where their multidimensional well-being and inequality scores vary dramatically when the dimensions are seen more of complements or perfect substitutes. On the other hand, the western and northern regions of Europe (e.g., regions of Norway, Sweden, Germany, Finland, Iceland, the UK, Denmark, Austria, Netherlands, France, Ireland, and Belgium) have balanced achievements across the dimensions of well-being, which leads to high multidimensional well-being scores and low multidimensional inequality within these countries irrespective of the interaction levels between the dimensions. We also examined the over-time changes in the multidimensional well-being in the European regions between 2000 and 2014, and found that multidimensional well-being improved and inequality decreased in personal and community categories but remained unchanged in material well-being category across the European regions between 2000 and 2014 irrespective of interaction levels between wellbeing dimensions.

We also examine the redundancy of composite indices that are obtained with different interactions between the dimensions. Even though these multidimensional well-being indices that are obtained with alternative interactions between the dimensions are highly and positively correlated, these indices with alternative interactions convey different multidimensional well-being and inequality outcomes, which then can lead to different policy implications. Furthermore, there is also a good range of rank reversals when different interaction levels between the dimensions (i.e., perfect substitution or more of a complementarity between the dimensions) are allowed.

We also examine some of the EU policy implications of the different interaction levels between the dimensions (i.e., the choice of the $\beta$ parameter in the generalized mean aggregation). In particular, we discuss whether the use of multidimensional well-being indices would have any effect on the choice of eligible regions for the EU structural funds. We find that the number of regions that are eligible for the funds differs depending on the interaction levels between the dimensions. If the dimensions are more seen as perfect substitutes (i.e., if the dimensions are aggregated through standard arithmetic mean aggregation procedure), there is always a less number of regions is eligible for the funds since this aggregation procedure produces a more equal distribution of composite achievements across the European regions. Whereas, if the dimensions are more seen as complements, there 
is higher number of regions eligible for the funds since the unbalanced composition of development (i.e., unbalanced achievements between the dimensions) are reflected in the composite outcomes, which leads to higher multidimensional inequality across the European regions. In particular, the inequality between the eastern and southern regions of the Europe and western and northern regions arises when the dimensions are more seen as complements. Hence, the choice of interaction levels between the dimensions has major EU policy implications.

In this paper, we aggregate the dimensions with a generalized mean aggregation procedure that is flexible enough to allow different levels of interaction between the dimensions. Since the 'true' interactions between the well-being dimensions are not known, interactions between the dimensions will be based on the choices of public and policymakers, which depend on their perceptions of well-being and policy targets. For instance, policymakers can determine set of well-being dimensions that are more seen as substitutes and therefore use arithmetic mean aggregation to obtain index outcomes. On the other hand, they can also cluster set of dimensions in which they prefer to obtain rounded achievements across the well-being dimensions (in this case, well-being dimensions are more seen as complements) and allow a different degree of complementarity by choosing a suitable $\beta$ parameter to use in the generalized mean aggregation procedure. If the policymakers are more (less) sensitive about the balanced composition of development between the well-being dimensions, their preferences can be reflected in the aggregation procedure by increasing (decreasing) the degree of complementarity with the change in $\beta$ parameter.

Acknowledgements Author would like to thank editor and two anonymous reviewers for their constructive and helpful comments. Author also gratefully acknowledges financial support from the Research Investment Fund of Edge Hill University.

Open Access This article is distributed under the terms of the Creative Commons Attribution 4.0 International License (http://creativecommons.org/licenses/by/4.0/), which permits unrestricted use, distribution, and reproduction in any medium, provided you give appropriate credit to the original author(s) and the source, provide a link to the Creative Commons license, and indicate if changes were made.

\section{Appendix}

see Table 12. 


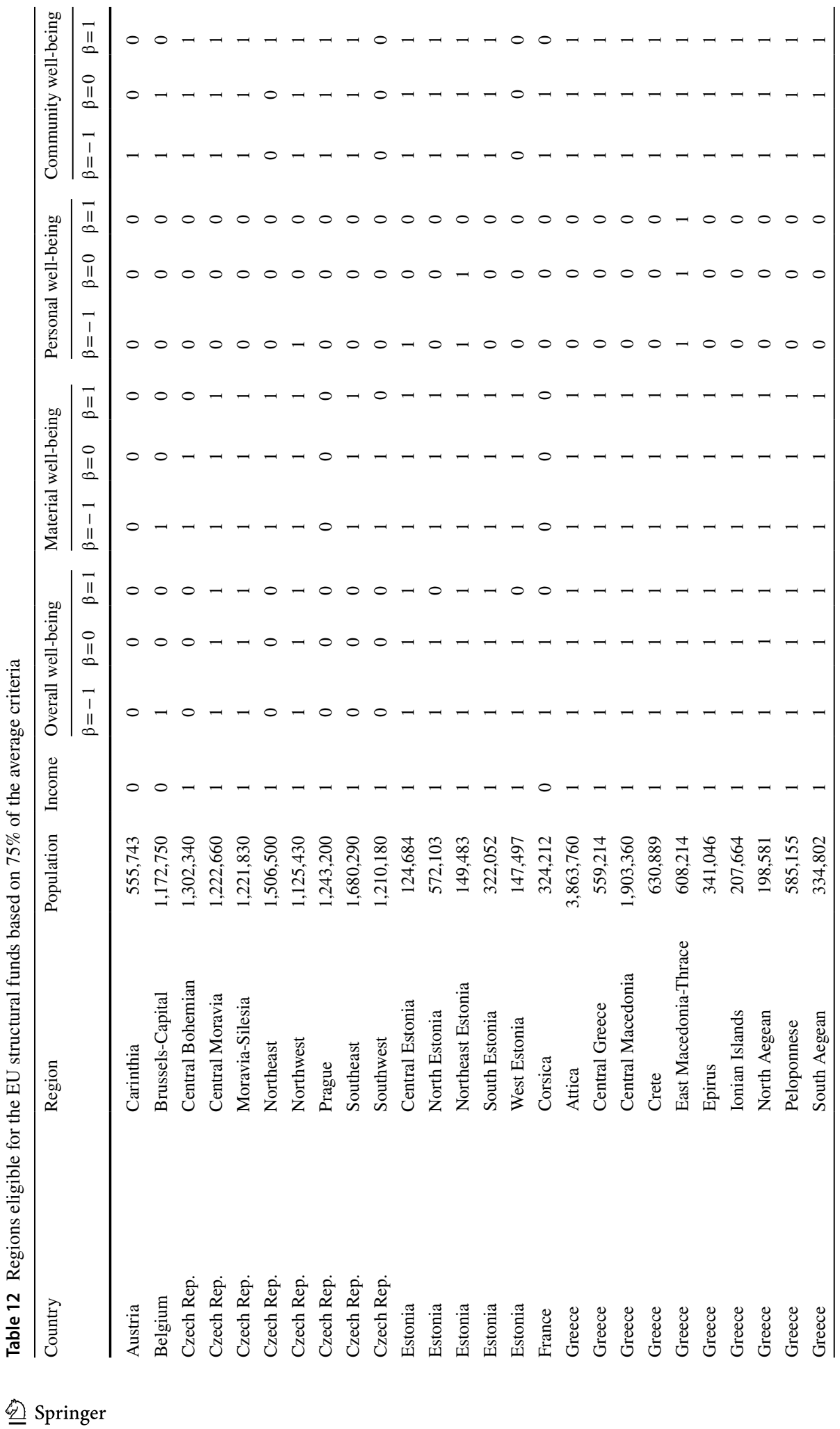




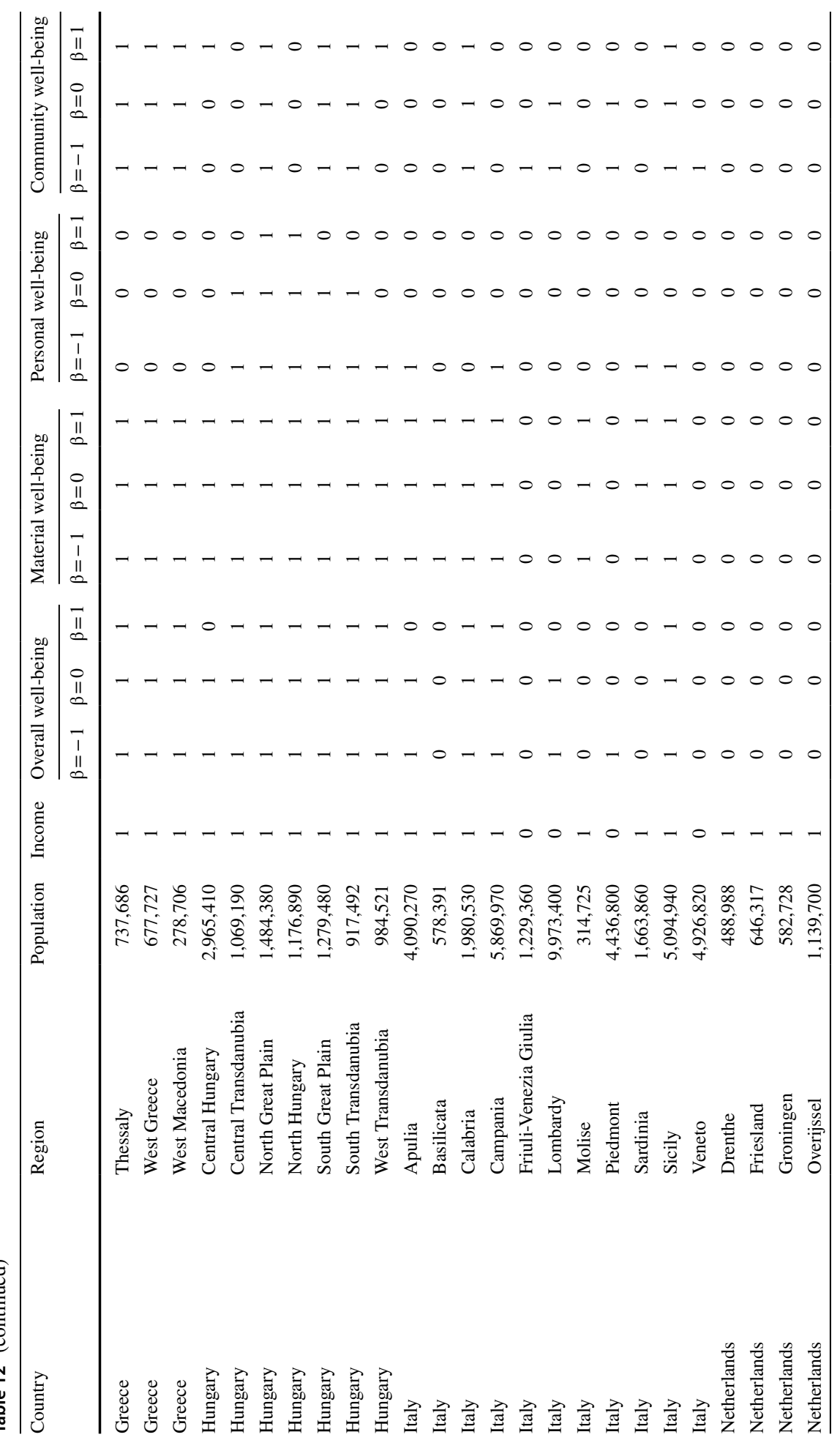




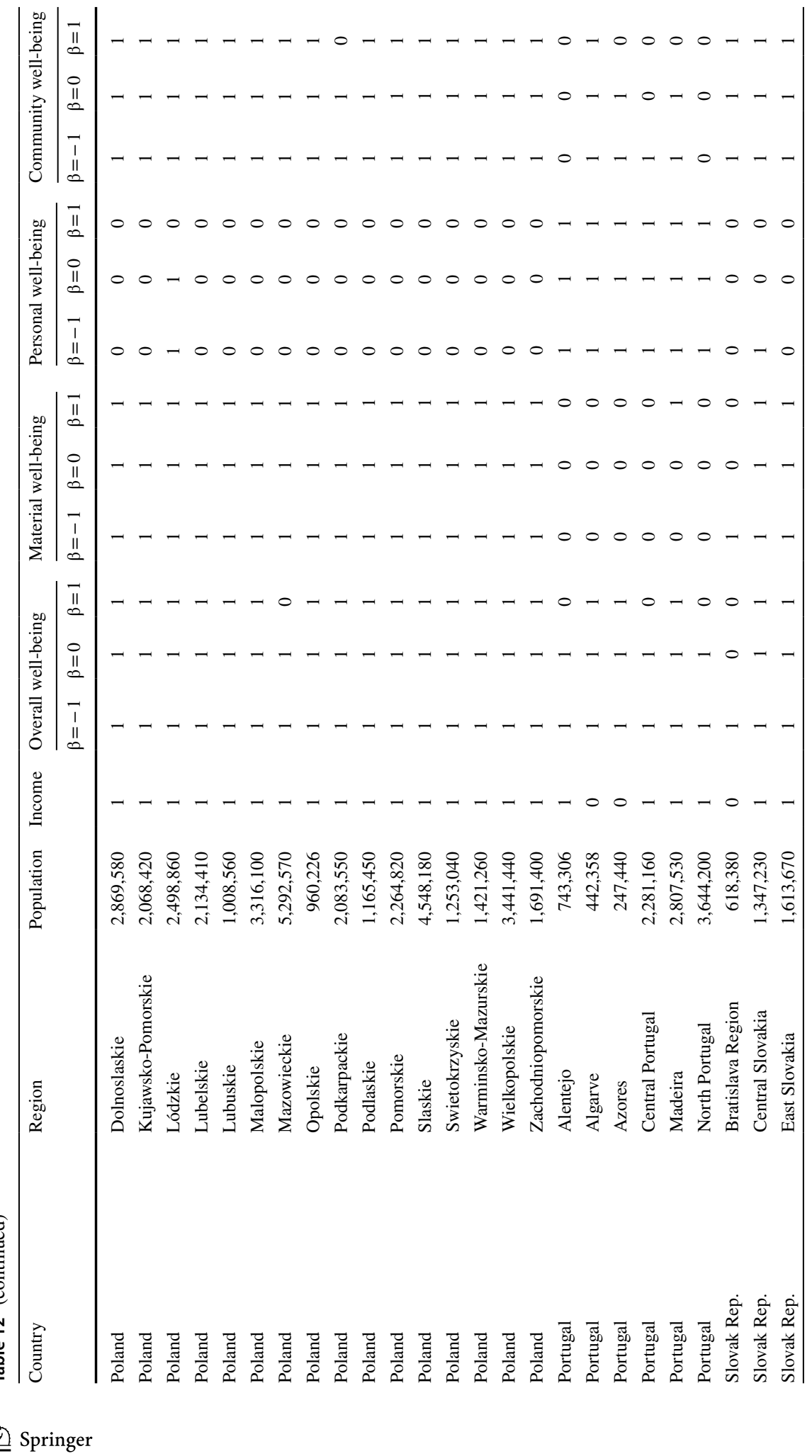




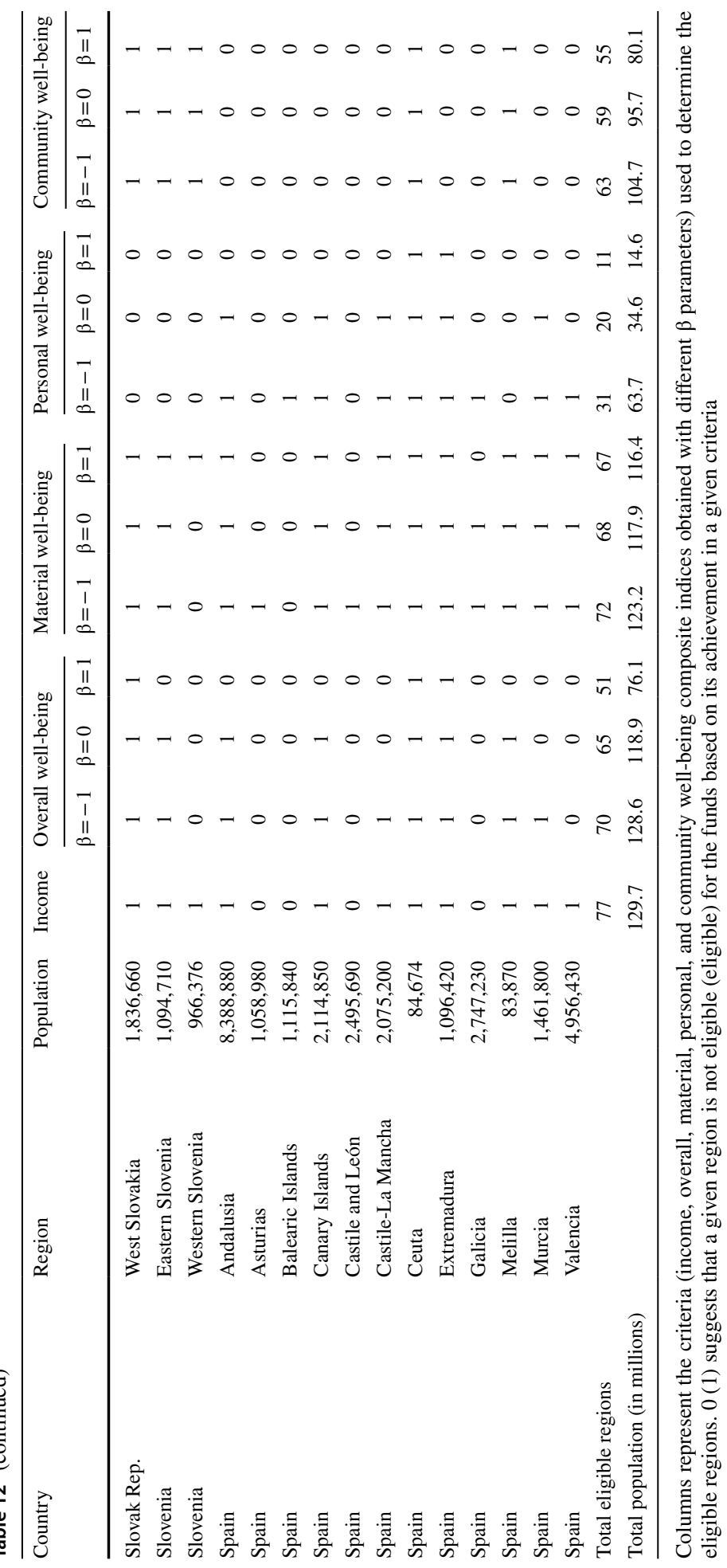




\section{References}

Alkire, S., \& Santos, M. A. (2014). Measuring acute poverty in the developing world: Robustness and scope of the Multidimensional Poverty Index. World Development, 59, 251-274.

Athanassoglou, S. (2015). Multidimensional welfare rankings under weight imprecision: A social choice perspective. Social Choice and Welfare, 44(4), 719-744.

Bárcena-Martín, E., Lacomba, B., Moro-Egido, A. I., \& Pérez-Moreno, S. (2014). Country differences in material deprivation in Europe. Review of Income and Wealth, 60(4), 802-820.

Becker, S. O., Egger, P., \& Von Ehrlich, M. (2013). Absorptive capacity and the growth and investment effects of regional transfers: Regression discontinuity design with heterogeneous treatment effects. American Economic Journal: Economic Policy, 5, 29-77.

Behrman, J. R., \& Rosenzweig, M. R. (2004). Returns to birthweight. Review of Economics and Statistics, $86,586-601$.

Berenger, V., \& Verdier-Chouchane, A. (2007). Multidimensional measures of well-being: Standard of living and quality of life across countries. World Development, 35(7), 1259-1276.

Bertin, G., Carrino, L., \& Giove, S. (2018). The Italian regional well-being in a multi-expert non-additive perspective. Social Indicators Research, 135(1), 15-51.

Binelli, C., Loveless, M., \& Whitefield, S. (2015). What is social inequality and why does it matter? Evidence from Central and Eastern Europe. World Development, 70, 239-248.

Bosker, M. (2009). The spatial evolution of regional GDP disparities in the 'old' and the 'new' Europe. Papers in Regional Studies, 88, 3-27.

Cahill, M. B. (2005). Is the human development index redundant? Eastern Economic Journal, 31(1), 1-5.

Carraro, C., Campagnolo, L., Eboli, F., Giove, S., Lanzi, E., Parrado, R., et al. (2013). The FEEM sustainability index: An integrated tool for sustainability assessment. In M. G. Erechtchoukova, P. A. Khaiter, \& P. Golinska (Eds.), Sustainability appraisal: Quantitative methods and mathematical techniques for environmental performance evaluation (pp. 9-32). Berlin: Springer.

Chakravarty, S. (2003). A Generalized Human Development Index. Review of Development Economics, 7 , 99-114.

Chakravarty, S. (2011). A reconsideration of the tradeoffs in the new Human Development Index. Journal of Economic Inequality, 9, 471-474.

Cherchye, L., Ooghe, E., \& van Puyenbroeck, T. (2008). Robust human development rankings. Journal of Economic Inequality, 6(4), 287-321.

Chowdhury, S., \& Squire, L. (2006). Setting weights for aggregate indices: An application to the commitment to development index and human development index. Journal of Development Studies, 42(5), 761-771.

Coltman, T., Devinney, T. M., Midgley, D. F., \& Venaik, S. (2008). Formative versus reflective measurement models: Two applications of formative measurement. Journal of Business Research, 61(12), $1250-1262$.

Decancq, K. (2017). Measuring multidimensional inequality in the OECD member countries with a distribution-sensitive Better Life Index. Social Indicators Research, 131, 1057-1086.

Decancq, K., Fleurbaey, M., \& Schokkaert, E. (2015). Inequality, income, and well-being. In A. B. Atkinson \& F. Bourguignon (Eds.), Handbook of income distribution (pp. 67-140). Amsterdam: Elsevier.

Decancq, K., \& Lugo, M. A. (2013). Weights in multidimensional indices of wellbeing: An overview. Econometric Reviews, 32, 7-34.

Decancq, K., \& Schokkaert, E. (2016). Beyond GDP: Using equivalent incomes to measure well-being in Europe. Social Indicators Research, 126, 21-55.

Diamantopoulos, A., Riefler, P., \& Roth, K. P. (2008). Advancing formative measurement models. Journal of Business Research, 61(12), 1203-1218.

Doran, J., \& Jordan, D. (2013). Decomposing European NUTS2 regional inequality from 1980 to 2009 : National and European policy implications. Journal of Economic Studies, 40(1), 22-38.

Duclos, J.-Y., \& Gregoire, P. (2002). Absolute and relative deprivation and the measurement of poverty. Review of Income and Wealth, 48(4), 471-492.

Durand, M. (2015). The OECD better life initiative: How's life? And the measurement of well-being. Review of Income and Wealth, 61, 4-17.

Esty, D. C., Levy, M., Srebotnjak, T., \& De Sherbinin, A. (2005). 2005 Environmental sustainability index: Benchmarking national environmental stewardship. New Haven: Yale Center for Environmental Law \& Policy.

European Commission. (2010). Europe 2020. A strategy for smart, sustainable and inclusive growth. COM (2010) 2020 final. 
European Committee of the Regions. (2011). Opinion of the committee of the regions on 'measuring progress-GDP and beyond'. Official Journal of the European Union, C, 015(04), 17-22.

European Parliament and Council of the European Union. (2013). Regulation (EU) No 1303/2013 of the European Parliament and of the council. Official Journal of the European Union, 347, 320-469.

Fleurbaey, M., \& Blanchet, D. (2013). Beyond GDP: Measuring welfare and assessing sustainability. Oxford: Oxford University Press.

Foster, J. E. (1998). Absolute versus relative poverty. American Economic Review, 88(2), 335-341.

Foster, J. E., McGillivray, M., \& Seth, S. (2013). Composite indices: Rank robustness, statistical association, and redundancy. Econometric Reviews, 32(1), 35-56.

Fredriksen, K. (2012). Income inequality in the European Union. OECD Economics Department, working papers no. 952, OECD Publishing.

Garmendia, E., \& Gamboa, G. (2012). Weighting social preferences in participatory multi-criteria evaluations: A case study on sustainable natural resource management. Ecological Economics, 84, 110-120.

Glaeser, E., La Porta, R., Lopez-de-Silanes, F., \& Shleifer, A. (2004). Do institutions cause growth? Journal of Economic Growth, 9, 271-303.

Guh, Y. Y., Po, R. W., \& Lee, E. S. (2008). The fuzzy weighted average within a generalized means function. Computers \& Mathematics with Applications, 55(12), 2699-2706.

Herrero, C., Martinez, R., \& Villar, A. (2010). Multidimensional social evaluation. An application to the measurement of human development. Review of Income and Wealth, 56, 483-497.

Hoffmeister, O. (2009). The spatial structure of income inequality in the enlarged EU. Review of Income and Wealth, 55, 101-127.

Klugman, J., Rodriguez, F., \& Choi, H. (2011). The HDI 2010: New controversies, old critiques. Journal of Economic Inequality, 9, 249-288.

Malik, K. (2013). Human development report 2013: The rise of the global south-Human progress in a diverse world. New York: United Nations.

Mazziotta, M., \& Pareto, A. (2016). On a Generalized Non-compensatory Composite Index for measuring socio-economic phenomena. Social Indicators Research, 127, 983-1003.

Mazziotta, M., \& Pareto, A. (2017). Synthesis of indicators: The composite indicators approach. In F. Maggino (Ed.), Complexity in society: From indicators construction to their synthesis. Social indicators research series (Vol. 70, pp. 159-191). Cham: Springer.

Mazziotta, M., \& Pareto, A. (2018). Use and misuse of PCA for measuring well-being. Social Indicators Research, 1, 1. https://doi.org/10.1007/s11205-018-1933-0.

McGillivray, M. (2005). Measuring non-economic well-being achievement. Review of Income and Wealth, 51(2), 337-364.

Merad, M., Dechy, N., Serir, L., Grabisch, M., \& Marcel, F. (2013). Using a multi-criteria decision aid methodology to implement sustainable development principles within an organization. European Journal of Operational Research, 224(3), 603-613.

Meyer, P., \& Ponthiere, G. (2011). Eliciting preferences on multiattribute societies with a Choquet integral. Computational Economics, 37(2), 133-168.

Notten, G., \& De Neubourg, C. (2011). Monitoring absolute and relative poverty: "Not enough" is not the same as "much less". Review of Income and Wealth, 57(2), 247-269.

OECD. (2008). Handbook on constructing composite indicators. Methodology and user guide. Paris: OECD Publications.

OECD. (2014). How's life in your region? Measuring regional and local well-being for policy making. Paris: OECD Publications.

OECD. (2016). OECD regional well-being: A user's guide. https://www.oecdregionalwellbeing.org/assets/ downloads/Regional-Well-Being-User-Guide.pdf. Accessed 6 Aug 2018.

Permanyer, I. (2011). Assessing the robustness of composite indices rankings. Review of Income and Wealth, 57(2), 306-326.

Pinar, M., Cruciani, C., Giove, S., \& Sostero, M. (2014). Constructing the FEEM sustainability index: A Choquet integral application. Ecological Indicators, 39, 189-202.

Pinar, M., Stengos, T., \& Topaloglou, N. (2013). Measuring human development: A stochastic dominance approach. Journal Economic Growth, 18(1), 69-108.

Pinar, M., Stengos, T., \& Topaloglou, N. (2017). Testing for the implicit weights of the dimensions of the Human Development Index using stochastic dominance. Economics Letters, 161, 38-42.

Pinar, M., Stengos, T., \& Yazgan, M. E. (2015). Measuring human development in the MENA region. Emerging Markets Finance and Trade, 51(6), 1179-1192.

Ravallion, M. (1997). Good and bad growth: The human development reports. World Development, 25, 631-638. 
Ravallion, M. (2012). Troubling tradeoffs in the Human Development Index. Journal of Development Economics, 99, 201-209.

Rowley, H. V., Peters, G. M., Lundie, S., \& Moore, S. J. (2012). Aggregating sustainability indicators: Beyond the weighted sum. Journal of Environmental Management, 111, 24-33.

Stiglitz, J. E., Sen, A., \& Fitoussi, J.-P. (2009). Report by the commission on the measurement of economic performance and social progress. Paris: Commission on the Measurement of Economic Performance and Social Progress.

Tofallis, C. (2013). An automatic-democratic approach to weight setting for the new human development index. Journal of Population Economics, 26(4), 1325-1345.

Zambrano, E. (2014). An axiomatization of the Human Development Index. Social Choice and Welfare, 42, 853-872.

Zambrano, E. (2017). The 'troubling tradeoffs' paradox and a resolution. Review of Income and Wealth, 63(3), 520-541. 